\title{
Relationship between the Hormonal Balance and the Regulation of Iron Deficiency Stress Responses in Cucumber
}

\author{
Eva Bacaicoa, Ángel María Zamarreño, Diane Leménager, and Roberto Baigorri \\ CIPAV TimacAGRO International-Roullier Group, Polígono Arazuri-Orcoyen, $c / C n^{\circ} 32,31160$ \\ Orcoyen (Navarra) Spain \\ José María García-Mina ${ }^{1}$ \\ Department of Chemistry and Soil Chemistry, Faculty of Sciences, University of Navarra, P.O. Box \\ 273, 31080 Pamplona (Navarra) Spain and CIPAV TimacAGRO International-Roullier Group, \\ Polígono Arazuri-Orcoyen, c/C n 32, 31160 Orcoyen (Navarra) Spain
}

\begin{abstract}
AdDITIONAL INDEX wORDS. indole-3-acetic acid, abscisic acid, cytokinins, ethylene, Fe(III)-chelate reductase activity, $\mathrm{H}^{+}-$ ATPase, gene expression

Abstract. Some studies suggest that iron (Fe) stress root responses are regulated by variations in specific plant hormones. However, this question remains unclear. A time-course experiment dealing with the relationship between the expression of the Fe-stress root responses at transcriptional (CsFRO1, CsIRT1, CsHA1, and CsHA2) and enzymatic levels [root $\mathrm{Fe}$ (III)-chelate reductase and plasma membrane $\mathrm{H}^{+}$-ATPase], and the variation of phytohormone concentrations in the shoot and root of $\mathrm{Fe}$-starved plants have been studied in a Fe-efficient cucumber cultivar (Cucumis sativus L. cv. Ashley). The results indicate that the expression over time of the physiological Festress root responses at transcriptional and enzyme activity levels are consistent with significant increases in indole3-acetic acid root (transient) and shoot (sustained) concentrations. Fe-starvation also caused transient changes in the root concentration of abscisic acid and nitric oxide. Finally, an increase in root ethylene production and a decrease in the root concentration of some cytokinins were observed under Fe starvation, but they were not clearly timely coordinated with the expression of $\mathrm{Fe}$ physiological root responses.
\end{abstract}

One of the most significant nutritional disorders affecting plant development in calcareous soils is Fe deficiency (ÁlvarezFernández et al., 2006; Hansen et al., 2006; Rombolà and Tagliavini, 2006). In this type of soil, the simultaneous presence of high concentrations of bicarbonate and high alkaline $\mathrm{pH}$ values causes Fe precipitation, which is associated with the unavailability of $\mathrm{Fe}$ for plants and microorganisms (Abadía et al., 2004; Lucena, 2006; Robin et al., 2008). To deal with this problem, plants have developed specific mechanisms aimed at increasing available rhizospheric $\mathrm{Fe}$ and the ability to absorb and assimilate Fe (Kawai and Alam, 2006; Schmidt, 2006). Dicots and nongrass monocots plants activate specific root responses to Fe deficiency. Among them are the acidification of the rhizosphere, the enhancement of the reduction of $\mathrm{Fe}(\mathrm{III})$ to $\mathrm{Fe}(\mathrm{II})$ at the root surface, the enhancement of the transport of $\mathrm{Fe}(\mathrm{II})$ into the root system, the release of reductants to the rhizosphere, and the development of morphological changes in the roots, principally subapical swelling and root hairs (Briat, 2008; Curie and Briat, 2003; Schmidt, 2006). Most of these responses are associated with the upregulation of several Fe-regulated genes such as the $\mathrm{H}^{+}$-ATPase, the ferric reductase, and the iron transporter genes (Curie and Briat, 2003).

Received for publication 30 July 2009. Accepted for publication 18 Nov. 2009. This research was funded by the Roullier Group and the Government of Navarra.

We thank Dr. Francisco Javier Romera for his valuable remarks that improved the quality of the manuscript and David Rhymes for kindly improving the English of the manuscript.

${ }^{1}$ Corresponding author. E-mail: jgmina@timacagro.es.
Similarly, graminaceous plants have developed alternative mechanisms principally based on the synthesis and release to the rhizosphere of specific chelating agents, named phytosiderophores, capable of complexing Fe and other micronutrients, and on the production of Fe-phytosiderophore transporters to absorb them into the root system (Kawai and Alam, 2006).

Split-root assays show that development regulation in $\mathrm{Fe}-$ deficient plants is directly associated with physiological and biochemical responses related to $\mathrm{Fe}$ status in root and shoot (Vert et al., 2003). However, the nature of these regulation processes is poorly known. In fact, a previous work carried out in cucumber plants showed that the regulation of the expression of the physiological Fe deficiency stress root responses is greatly affected by the efficiency of the plants to optimize and use the available Fe in the shoot (Bacaicoa and García-Mina, 2009).

Certain studies involving specific hormonal precursors and functional inhibitors suggest that the regulation of $\mathrm{Fe}$ deficiency stress responses might be related to variations of the concentration of certain hormones in the roots (Romera et al., 2006; Rubio et al., 2009). Studies conducted by Landsberg and coworkers stressed the possible intervention of auxins in the regulation of $\mathrm{Fe}$ deficiency stress root responses (Landsberg, 1981a, 1981b, 1981c, 1984; Römheld and Marschner, 1986). Likewise, the studies of Romera and coworkers strongly suggest an important role for ethylene in such a regulation (Lucena et al., 2006; Romera and Alcántara, 2004; Romera et al., 2006; Waters et al., 2007). Lamattina and coworkers (Graziano et al., 2002; Graziano and Lamattina, 2007) and others (Murgia et al., 2002) have noted the significant influence of nitric oxide $(\mathrm{NO})$ in the regulation of $\mathrm{Fe}$ homeostasis in the 
shoot and in the expression of Fe stress responses in the roots. Finally, Séguéla et al. (2008) reported the capacity of different types of cytokinins (CKs) to repress the expression of FRO2, IRT1, and FIT genes in arabidopsis [Arabidopsis thaliana (L.) Heynh.] by means of a mechanism different from that involved in the activation of these genes by Fe deficiency.

There are several studies that have questioned the determinant role of hormones in the regulation of Fe deficiency stress root responses. Schmidt et al. (2000b), in working with arabidopsis mutants and altering their sensitivity to specific hormones, observed that none of the hormones studied [including ethylene, indole-3-acetic acid (IAA), and abscisic acid (ABA) ] appeared to have an important role in the regulation of Fe deficiency stress responses.

In principle, the mechanism by which plant hormones can affect biochemical processes involves different and complementary pathways. It can be expressed in changes in the local concentration of these hormones in specific areas of the root and/or shoots, or in the sensitivity of specific areas of the plant to hormone action. Although these changes may not always be related to measurable changes in the total concentration of the hormone in the whole plant, they are normally well correlated with changes in the concentration of the hormone in the plant area studied: root, stem, or leaf, principally in young plants (Davies, 2004). It also becomes clear that these events affecting hormone plant distribution must be timely coordinated with the functional expression of the hormone effect. However, the analysis of the differences between the distribution within the plant of the main plant regulators in Fe-starved and Fesufficient plants is scarce. Only two studies report data related to IAA levels in the roots of Fe-deficient plants, one in sunflower [Helianthus annuus L. (Römheld and Marschner, 1986)] and the other one in apple [Malus baccata (L.) Borkh. and M. baccata var. xiaojinensis (M.H. Cheng \& N.G. Jiang) Ponomar. (Han et al., 2005)]. In the case of ethylene, there are more studies reporting significant increases in this hormone in the roots of different Fe-deficient plant species (Romera et al., 1999, 2006). However, the synchronization in time between root ethylene increases and the expression of Fe deficiency root responses is still controversial ( $\mathrm{Li}$ and $\mathrm{Li}, 2004$ ). Finally, all these analytical studies have been carried out in roots, but if a shoot-to-root systemic signal is involved in the control of Fe deficiency responses, the analysis of the pattern of hormone variation in the shoots may be of great importance.

In this context, a complementary study dealing with the time-course relationship between the gene expression and enzyme activity of the main physiological Fe deficiency root responses and the hormonal balance in the whole plant (root and shoot) might clarify this controversy. This study could permit us to know what type of hormone is affected by Fe deficiency and if the change is compatible (timely synchronized) with a role in the induction of the main Fe deficiency root responses.

Thus, the objective of this work was to study the time-course variation in the concentrations of the main hormones [ethylene, IAA, ABA, gibberellins (GAs), $\mathrm{NO}$, and $\mathrm{CKs}$ ] in roots and shoots and the expression of the main Fe-regulated genes isolated in roots [Fe(III)-chelate reductase, $\mathrm{Fe}(\mathrm{II})$-transporter, and $\mathrm{H}^{+}$-ATPase] in cucumber plants subjected to Fe starvation. In addition, we have analyzed in these plants the enzyme activity of the $\mathrm{Fe}$ (III)-chelate reductase and the $\mathrm{H}^{+}$-ATPase. An Fe-efficient cucumber cultivar, Ashley (Bacaicoa and García-Mina, 2009), was employed for the experiments.

\section{Materials and Methods}

Plant material and growth Conditions. Seeds of 'Ashley' cucumber were germinated for 1 week in perlite moistened with $1 \mathrm{~mm}$ calcium sulfate solution. In the $10 \mathrm{~d}$ following postgermination, the plants were irrigated with an aerated nutrient solution having a $\mathrm{pH}$ of 6.0 described by Romera et al. (1999) as: $2 \mathrm{~mm} \mathrm{Ca}\left(\mathrm{NO}_{3}\right)_{2}, 0.75 \mathrm{~mm} \mathrm{~K}_{2} \mathrm{SO}_{4}, 0.65 \mathrm{~mm} \mathrm{MgSO}_{4}, 0.5 \mathrm{~mm}$ $\mathrm{KH}_{2} \mathrm{PO}_{4}, 50 \mu \mathrm{M} \mathrm{KCl}, 10 \mu \mathrm{M} \mathrm{H}_{3} \mathrm{BO}_{3}, 1 \mu \mathrm{M} \mathrm{MnSO}_{4}, 0.5 \mu \mathrm{M}$ $\mathrm{CuSO}_{4}, 0.5 \mu \mathrm{M} \mathrm{ZnSO}_{4}$, and $0.35 \mu \mathrm{M} \mathrm{Na} \mathrm{MoO}_{4}$ containing $1 \mu \mathrm{M}$ Fe-HBED (Fe-N, N'di-ortho hydroxibenzyl ethylene diamine diacetate). After $10 \mathrm{~d}$, the plants [separated into two groups corresponding to the treatments: $40 \mu \mathrm{M}$ Fe-HBED $(+\mathrm{Fe})$ and $0 \mu \mathrm{M}$ Fe-HBED (-Fe)] were transferred to a continuously aerated solution. One hour before treatments and after 1, 2, 3, $4,5,7,9$, and $11 \mathrm{~d}$ from the onset of the treatments, the plants were harvested and samples corresponding to the root and shoot were collected to carry out the different analytical determinations as described below. The results concerning the different parameters analyzed were expressed from the first day after $\mathrm{Fe}$ starvation. There were not noticeable differences between the results corresponding to plants receiving Fe harvested $1 \mathrm{~h}$ before treatments and Fe-sufficient plants harvested the first day after treatments.

The plants were cultivated in a growth chamber [photosynthetic photon flux $\left.(P P F)=250 \mu \mathrm{mol} \cdot \mathrm{m}^{-2} \cdot \mathrm{s}^{-1}\right]$ at a photoperiod of $15 / 9 \mathrm{~h}$ day/night, an average temperature of $23 / 21{ }^{\circ} \mathrm{C}$ day/ night, and a relative humidity of $60 \%$ to $75 \%$.

The whole experiment was carried out twice, and representative results are presented.

Parameters evaluated in the experiments. The effect of Fe deficiency on Fe stress root plant responses was evaluated through the analysis of the following parameters.

FERric Chelate REDUCTION BY INTACT ROOTS. Fe(III)-chelate reduction by roots of cucumber plants was measured as reported by Pinton et al. (1999) using the bathophenanthroline disulfonate (BPDS) reagent. Briefly, $1 \mathrm{~g}$ of roots from a single plant was incubated in darkness at $25^{\circ} \mathrm{C}$ in $5.25 \mathrm{~mL}$ of the nutrient solution at $\mathrm{pH} 5.5$, containing $0.387 \mathrm{~mm}$ Fe(III)-EDTA and $0.286 \mathrm{~mm}$ BPDS. After $30 \mathrm{~min}$, the absorbance of the solution was measured at $535 \mathrm{~nm}$ using a spectrophotometer (model 8453; Agilent Technologies, Santa Clara, CA) running ultraviolet-visible Chemstation Software (Agilent Technologies). The quantity of Fe(III) reduced was calculated by the concentration of the Fe(II)-BPDS complex formed, using an extinction coefficient of $22.1 \times 10^{-3} \mathrm{M}^{-1} \cdot \mathrm{cm}^{-1}$. We observed in previous experiments a good reproducibility of the results obtained using this method, as well as a good correlation between these results and those obtained using the whole root of the plant (data not shown).

REAL-TIME REVERSE TRANSCRIPTASE CHAIN REACTION (RTPCR) ANALYSIS OF MRNA TRANSCRIPT. The roots of the plants were collected and disrupted with liquid nitrogen prior to RNA extraction. Total RNA was extracted from $60 \mathrm{mg}$ of crushed root using $350 \mu \mathrm{L}$ of guanidine- $\mathrm{HCl}$ lysis buffer of NucleoSpin RNA Plant Kit (Macherey-Nagel, Diirefn, Germany) and 3.5 $\mu \mathrm{L}$ of $\beta$-mercaptoethanol with a rotor-stator for $45 \mathrm{~s}$ following the manufacturer's instructions. The DNase-treated RNA was quantified by measuring the absorbance of the pooled elution at $260 \mathrm{~nm}$. The RNA quality was confirmed as a $260 / 280 \mathrm{~nm}$ ratio above 1.8 . The integrity of RNA was verified by electrophoresis on $1 \%$ formaldehyde agarose gels stained with SYBR Gold. 
The absence of genomic DNA was initially checked in a realtime PCR containing $50 \mathrm{ng}$ of total RNA (without reverse transcription) and $\alpha$-tubulin-specific primers (CsTual). The absence of inhibitors in $250 \mathrm{ng}$ of RNA samples was also checked by SPUD assay with SYBR Green (Nolan et al., 2006). First-strand cDNA synthesis was carried out in $20-\mu \mathrm{L}$ reactions containing $1 \mu \mathrm{g}$ of RNA with RNase $\mathrm{H}^{+}$MMLV reverse transcriptase iScript and a mix of oligo(dT) and random primers from iScript cDNA Synthesis Kit (Bio-Rad Laboratories, Hercules, CA). The reverse transcription was made up for $5 \mathrm{~min}$ at $25^{\circ} \mathrm{C}, 30 \mathrm{~min}$ at $42{ }^{\circ} \mathrm{C}$, and ended by $5 \mathrm{~min}$ at $85^{\circ} \mathrm{C}$. The quality of cDNAs was verified by $5^{\prime}-3^{\prime}$ ratio (performing realtime PCR with $\alpha$-tubulin-specific primers: CsTua 4 in $5^{\prime}$ strand and CsTua 6 in 3' strand; Table 1). Real-time RT-PCR was performed on $50 \mathrm{ng}$ of cDNA using iQ SYBR Green supermix containing hot-start iTaq DNA polymerase in an iCycler iQ (Bio-Rad Laboratories). Primer pairs used to amplify cucumber plasma membrane $\mathrm{H}^{+}$-ATPase genes (CsHAl and CsHA2), a $\mathrm{Fe}$ (III)-chelate reductase gene (CsFROI), a Fe(II)-transporter gene (CsIRT1), and a $\alpha$-tubulin (reference gene) were designed with Beacon Premier Biosoft Software and were synthesized by Sigma-Genosys (Cambridge, United Kingdom) (Table 1). The real-time PCR program consist of an iTaq DNA polymerase activation at $95^{\circ} \mathrm{C}$ for $3 \mathrm{~min}$, followed by 40 amplification cycles (denaturing step for $10 \mathrm{~s}$ at $95{ }^{\circ} \mathrm{C}$; an annealing step for $10 \mathrm{~s}$ at $62{ }^{\circ} \mathrm{C}$, and an elongation step for $10 \mathrm{~s}$ at $72{ }^{\circ} \mathrm{C}$ during which the fluorescence data were collected). To confirm PCR products, a melting curve was performed by heating the samples from 72 to $98{ }^{\circ} \mathrm{C}$ in $0.1{ }^{\circ} \mathrm{C}$ increments with a dwell time at each temperature of $10 \mathrm{~s}$ during which the fluorescence data were collected. The melting temperature of the products was determined with the iCycler iQ Optical System 3.1 Software (Bio-Rad Laboratories). The reaction efficiency of PCR (comprising between 1.99 and 2.02) was determined on the slope of standard dilution curves of pooled cDNAs with each specific primer pairs at harvest times. Target gene expression was normalized to $\alpha$-tubulin expression. Relative expression (n-fold) of the normalized target gene in the Festarved plants was calculated with the REST C) software [REST-MCS beta 2.0 (Pfaffl et al., 2002)] via comparison with
Fe-sufficient plants considering efficiency values according to the mathematical model proposed by Pfaffl et al. (2002).

Isolation of Plasma Membrane Vesicles AND ATPASE ASSAYS. Plasma membrane (PM) vesicles were isolated from plant roots using a sucrose gradient technique as described previously by Pinton et al. (1999) and Santi et al. (2003). Briefly, the root segments corresponding to the different treatments were cut separately and ground with a pestle in an ice-cold homogenization medium containing $250 \mathrm{~mm}$ sucrose, $10 \%$ (v/v) glycerol, $10 \mathrm{~mm}$ glycerol-1-phosphate, $2 \mathrm{~mm} \mathrm{MgSO}_{4}$, 2 mм EDTA, 2 mм EGTA, 2 mм ATP, 2 mм DTT (dithiothreitol), 5.7\% (w/v) chorine-iodine, $1 \mathrm{mM}$ PMFS, $20 \mu \mathrm{g} \cdot \mathrm{mL}^{-1}$ chymostatin, and $25 \mathrm{~mm}$ BTP $\{1,3$-bis [TRIS(hydroxymethyl)methylamino]propane $\}$ buffered to $\mathrm{pH} 6.7$ with MES. About $2.5 \mathrm{~mL}$ per fresh weight of root tissues was used. The homogenates were filtered through four layers of cheesecloth and subjected to $3 \mathrm{~min}$ of centrifugation at $13,000 \mathrm{~g}_{\mathrm{n}}$ at $4{ }^{\circ} \mathrm{C}$ (Microfuge 22R centrifuge; Beckman Coulter, Fullerton, CA). The pellets were discarded and the suspension was centrifuged for a further $25 \mathrm{~min}$ under the same conditions. The pellets were then recovered, gently resuspended in $400 \mu \mathrm{L}$ of homogenization medium, and loaded onto discontinuous density gradients made by layering $700 \mu \mathrm{L}$ of $25 \%(\mathrm{w} / \mathrm{w})$ sucrose over $300 \mu \mathrm{L}$ of $38 \%(\mathrm{v} / \mathrm{v})$ sucrose cushion in $1.5-\mathrm{mL}$ tubes. Both sucrose

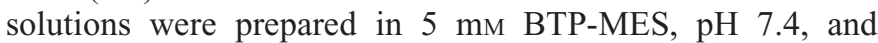
contained all the protectants present in the homogenization medium. The gradients were centrifuged for $1 \mathrm{~h}$ at $13,000 \mathrm{~g}_{\mathrm{n}}$, and the vesicles banding at the $25 \% / 38 \%$ interface were collected, diluted, and prepared for enzyme activity measurements.

The PM H $\mathrm{H}^{+}$-ATPase activity was determined according to Santi et al. (2005) and Forbush (1983). Assays were performed at $38^{\circ} \mathrm{C}$ in a $0.6 \mathrm{~mL}$ reaction volume containing $50 \mathrm{~mm}$ MES-BTP, pH 6.5, $5 \mathrm{~mm} \mathrm{MgSO}_{4}, 100 \mathrm{~mm} \mathrm{KNO}_{3}, 600 \mu \mathrm{M} \mathrm{Na}_{2} \mathrm{MoO}_{4}, 1.5 \mathrm{~mm}$ $\mathrm{NaN}_{3}, 5 \mathrm{~mm}$ ATP-BTP, pH 6.5, and $0.01 \%(\mathrm{w} / \mathrm{v})$ Brij 58 (polyoxyethylene 20 cetyl ether) with or without $100 \mu \mathrm{M} \mathrm{V}_{2} \mathrm{O}_{5}$. The reaction was started with the addition of membrane vesicles ( $0.5 \mu \mathrm{g}$ of total protein); after $30 \mathrm{~min}$, the reaction was blocked and color developed as described in Varanini et al. (1993). Inorganic phosphate content was determined spectrophotometrically at $705 \mathrm{~nm}$ using an Agilent 8453 spectrophotometer running

Table 1. Primer sequences used in the gene expression studies of Fe-starved $(0 \mu \mathrm{M})$ and Fe-sufficient $(40 \mu \mathrm{M})$ cucumber plants.

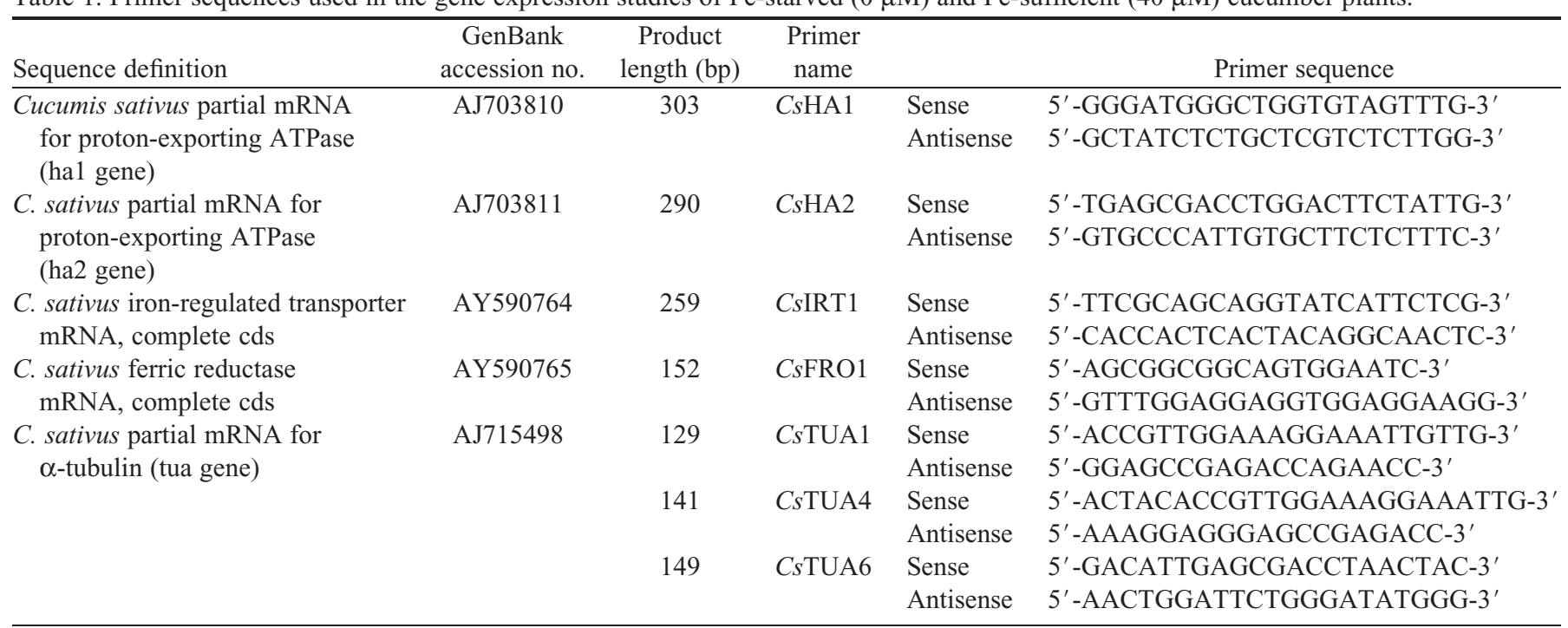


ultraviolet-visible Chemstation Software (Agilent Technologies) and $\mathrm{PM} \mathrm{H} \mathrm{H}^{+}$-ATPase activity was expressed as that inhibited by $100 \mu \mathrm{M}$ vanadate. Protein contents were determined following Bradford technique using BSA as standard (Bradford, 1976).

DETERMINATION OF RHIZOSPHERE ACIDIFICATION AS A RESPONSE TO IRON DEFICIENCY. The plant's capacity to acidify the rhizosphere was evaluated studying $\mathrm{pH}$ changes in the nutrient solution over time (Pinton et al., 1999; Romera and Alcántara, 2004).

Analysis of Chlorophyll (CHL) CONCENTration. The leaf concentration of Chl was determined using the portable instrument SPAD-502 chlorophyll meter (Minolta, Osaka, Japan). Previously, a calibration curve was established measuring the Chl concentration corresponding to a selected group of SPAD readings. Chl leaf concentration was determined using the method described in Séstak et al. (1971).

Analysis of EThylene. Cucumber plants corresponding to each treatment were separated into shoots and roots. Measurements were performed in root tissue because shoot analyses were below detection limits. Fresh root samples (1.5 g) were weighed and immediately transferred into $20-\mathrm{mL}$ syringes with $200 \mu \mathrm{L}$ of deionized water. The syringes were sealed and dark incubated for $2 \mathrm{~h}$ at room temperature to allow ethylene production to subside. A 1-mL gas sample was withdrawn with a gas-tight syringe from the $20-\mathrm{mL}$ syringe and analyzed for ethylene by gas chromatography using a gas chromatograph (Trace GC 2000 Series; ThermoQuest, Milan, Italy) equipped with a GS-GasPro 1134332 column ( $30 \mathrm{~m} \times 0.32 \mathrm{~mm}$; Agilent Technologies $)$ and flame ionization detector (FID). The rate of ethylene evolution was expressed as a function of per unit fresh weight. Data samples were processed using Xcalibur 1.0 Software (ThermoQuest).

Determination of Plant hormone CONCENTRATions. The concentration of the principal plant regulators in the shoot and root of treated plants was analyzed using high-performance liquid chromatography (HPLC)/mass spectrometry (MS)/MS as described below. The following hormones were studied: IAA, ABA, gibberellic acid $\left(\mathrm{GA}_{3}\right)$, gibberellin $\mathrm{A}_{4}\left(\mathrm{GA}_{4}\right)$, gibberellin $\mathrm{A}_{7}\left(\mathrm{GA}_{7}\right)$, trans-zeatin $(\mathrm{Z})$, dihydrozeatin (DHZ), trans- and cis-zeatin riboside (t-ZR and c-ZR), dihydrozeatin riboside (DHZR), isopentenyladenine (iP), and isopentenyladenosine (iPR). The extraction and purification of the different plant regulators were carried out using the method described by Dobrev and Kamínek (2002) with some variations.

The analysis of IAA, ABA, and GAs content was as follows. Frozen plant tissue $(0.5 \mathrm{~g}$; previously triturated in a mortar to a powder with liquid nitrogen) was homogenized with $5 \mathrm{~mL}$ of precooled $\left(-20{ }^{\circ} \mathrm{C}\right)$ methanol:water $(80: 20, \mathrm{v} / \mathrm{v})$ and $2.5 \mathrm{~mm}$ sodium diethyldithiocarbamate. Deuteriumlabeled internal standards $\left\{\left[{ }^{2} \mathrm{H}_{5}\right]\right.$ indol-3-acetic acid (D-IAA); $\left[{ }^{2} \mathrm{H}_{6}\right]$ $(+)$-cis, trans-abscisic acid (DABA); and $\left[{ }^{2} \mathrm{H}_{2}\right]$ gibberellic acid $\left(\mathrm{D}-\mathrm{GA}_{3}\right)$ from Olchemim, Olomouc, Czech Republic $\}$ were added (100 $\mu \mathrm{L}$ of a stock solution of 400 $\mathrm{ng} \cdot \mathrm{mL}^{-1}$ of each standard in methanol) to the extraction medium. After overnight extraction at $-20{ }^{\circ} \mathrm{C}$, solids were separated by centrifugation at
$12,000 g_{\mathrm{n}}$ for $10 \mathrm{~min}$ at $4{ }^{\circ} \mathrm{C}$ using a Centrikon $\mathrm{T}-124$ centrifuge with an A8.24 rotor (Kontron Instruments, Cumbernauld, UK) and were re-extracted for $1 \mathrm{~h}$ with an additional $4 \mathrm{~mL}$ of extraction mixture. Supernatants were passed through a Strata C18-E cartridge $\left(3 \mathrm{~cm}^{3}, 200 \mathrm{mg}, 8 \mathrm{~B}-\mathrm{S} 001-\mathrm{FBJ}\right.$; Phenomenex, Torrance, CA) preconditioned with $4 \mathrm{~mL}$ of methanol followed by $2 \mathrm{~mL}$ of extraction medium. After evaporation at $40{ }^{\circ} \mathrm{C}$ until aqueous phase using a Vortex Evaporator (Labconco, KS City, $\mathrm{MO}), 0.5 \mathrm{~mL}$ of $1 \mathrm{M}$ formic acid was added. Afterward, the hormones were extracted successively with two portions of 5 and $4 \mathrm{~mL}$ of diethyl ether, and the organic phase was evaporated to dryness. The residue was redissolved in $250 \mu \mathrm{L}$ of methanol: $0.5 \%$ acetic acid $(40: 60, \mathrm{v} / \mathrm{v})$. The solution was centrifuged at $8,000 g_{\mathrm{n}}$ for $5 \mathrm{~min}$ before its injection in the LC/MS/MS system. The hormones were quantified by HPLC (2795 Alliance HT; Waters, Milford, MA) linked to a 3200 Q TRAP LC/MS/MS System (Applied Biosystems/MDS Sciex, Concord, ON, Canada) equipped with an electrospray interface, using an reverse-phase column (Synergi $4 \mu \mathrm{m}$ Hydro-RP $80 \mathrm{~A}, 150 \times 2 \mathrm{~mm}$; Phenomenex). A linear gradient of methanol (A) and $0.5 \%$ acetic acid in water (B) was used: $35 \%$ A for $1 \mathrm{~min}, 35 \%$ to $95 \% \mathrm{~A}$ in $9 \mathrm{~min}$, $95 \% \mathrm{~A}$ for $4 \mathrm{~min}$ and $95 \%$ to $35 \% \mathrm{~A}$ in $1 \mathrm{~min}$, followed by a stabilization time of $5 \mathrm{~min}$. The flow rate was $0.20 \mathrm{~mL} \cdot \mathrm{min}^{-1}$, the injection volume was $40 \mu \mathrm{L}$, and the column and sample temperatures were 30 and $20^{\circ} \mathrm{C}$, respectively. The detection and quantification were performed by multiple reaction monitoring (MRM) in the negative-ion mode, employing multilevel calibration curves with deuterated hormones as internal standards. Compounds dependents parameters are listed in Table 2. The source parameters were: curtain gas: $172.37 \mathrm{kPa}, \mathrm{GS} 1$ : $310.26 \mathrm{kPa}, \mathrm{GS} 2: 413.69 \mathrm{kPa}$, ion spray voltage: $-4000 \mathrm{~V}$, and temperature: $600{ }^{\circ} \mathrm{C}$. Data samples were processed using Analyst 1.4.2 software (Applied Biosystems/MDS Sciex).

The analysis of CKs content was as follows. Frozen plant tissue $(0.5 \mathrm{~g}$; previously triturated in a mortar to a powder with liquid nitrogen) was homogenized with $5 \mathrm{~mL}$ of precooled $\left(-20^{\circ} \mathrm{C}\right)$ methanol:water:formic acid $(15: 4: 1, \mathrm{v} / \mathrm{v} / \mathrm{v})$. Deuteriumlabeled CKs internal standards $\left\{\left[{ }^{2} \mathrm{H}_{5}\right]\right.$ trans-zeatin (D-Z); $\left[{ }^{2} \mathrm{H}_{5}\right]$ trans-zeatin riboside (D-ZR); $\left[{ }^{2} \mathrm{H}_{6}\right] \mathrm{N}^{6}$-isopentenyladenine (D-iP); and $\left[{ }^{2} \mathrm{H}_{6}\right] \mathrm{N}^{6}$-isopentenyladenosine (D-iPR); from Olchemim $\}$ were added $(40 \mu \mathrm{L}$ of a stock solution of 50 $\mathrm{ng} \cdot \mathrm{mL}^{-1}$ of each standard in methanol) to the extraction medium. After overnight extraction at $-20{ }^{\circ} \mathrm{C}$, solids were separated by centrifugation at $12,000 g_{\mathrm{n}}$ for $10 \mathrm{~min}$ at $4{ }^{\circ} \mathrm{C}$ using

Table 2. Optimal parameters for the multiple reaction monitoring detection of indol-3-acetic acid, abscisic acid, and gibberellins used in the HPLC mass spectrometry analysis of Fe-starved $(0 \mu \mathrm{M})$ and Fe-sufficient $(40 \mu \mathrm{M})$ cucumber plants.

\begin{tabular}{|c|c|c|c|c|c|c|c|}
\hline \multirow[b]{2}{*}{ Compound $^{z}$} & \multirow[b]{2}{*}{ Transition } & \multirow[b]{2}{*}{ Dwell (ms) } & \multicolumn{5}{|c|}{ Ionization and collision parameters ${ }^{y}$} \\
\hline & & & $\overline{\mathrm{DP}}$ & EP & CEP & $\mathrm{CE}$ & $\mathrm{CXP}$ \\
\hline IAA & $174.0>130.1$ & 150 & -30 & -3.0 & -12 & -14 & -4 \\
\hline $\mathrm{ABA}$ & $263.1>153.1$ & 150 & -25 & -3.5 & -20 & -16 & -4 \\
\hline $\mathrm{GA}_{3}$ & $345.1>143.1$ & 150 & -50 & -4.0 & -20 & -36 & -4 \\
\hline $\mathrm{GA}_{4}$ & $331.1>257.2$ & 200 & -55 & -7.0 & -16 & -28 & -5 \\
\hline $\mathrm{GA}_{7}$ & $329.1>223.2$ & 200 & -45 & -5.0 & -18 & -26 & -5 \\
\hline$\left[{ }^{2} \mathrm{H}_{5}\right] \mathrm{IAA}$ & $179.0>135.2$ & 150 & -20 & -7.0 & -12 & -14 & -4 \\
\hline$\left[{ }^{2} \mathrm{H}_{6}\right] \mathrm{ABA}$ & $269.1>159.2$ & 150 & -25 & -12 & -14 & -14 & -4 \\
\hline
\end{tabular}

${ }^{\mathrm{z}} \mathrm{AAA}=$ indol-3-acetic acid, $\mathrm{ABA}=$ abscisic acid, $\mathrm{GA}_{3}=$ gibberellic acid, $\mathrm{GA}_{4}=$ gibberellin $\mathrm{A}_{4}, \mathrm{GA}_{7}=$ gibberellin $\mathrm{A}_{7},\left[{ }^{2} \mathrm{H}_{5}\right] \mathrm{IAA}=\left[{ }^{2} \mathrm{H}_{5}\right]$ indol-3-acetic acid, $\left[{ }^{2} \mathrm{H}_{6}\right] \mathrm{ABA}=\left[{ }^{2} \mathrm{H}_{6}\right](+)$-cis, trans-abscisic acid. ${ }^{\mathrm{y}} \mathrm{DP}=$ declustering potential, $\mathrm{EP}=$ entrance energy, $\mathrm{CEP}=$ collision cell entrance potential, $\mathrm{CE}=$ collision energy, CXP = collision cell exit potential. 
a Centrikon T-124 centrifuge with an A8.24 rotor (Kontron Instruments) and were re-extracted for $1 \mathrm{~h}$ with an additional 4 $\mathrm{mL}$ of extraction mixture. Supernatants were passed through a Strata C18-E cartridge $\left(3 \mathrm{~cm}^{3}, 200 \mathrm{mg}, 8 \mathrm{~B}-\mathrm{S} 001-\mathrm{FBJ}\right.$; Phenomenex) preconditioned with $4 \mathrm{~mL}$ of methanol followed by $2 \mathrm{~mL}$ of extraction medium. After evaporation at $40{ }^{\circ} \mathrm{C}$ until aqueous phase using a Vortex Evaporator (Labconco), $2 \mathrm{~mL}$ of $1 \mathrm{M}$ formic acid was added and applied to an Oasis MCX column $\left(3 \mathrm{~cm}^{3}, 60 \mathrm{mg}, 186000254\right.$; Waters $)$ preconditioned with $4 \mathrm{~mL}$ of methanol and $2 \mathrm{~mL}$ of $1 \mathrm{M}$ formic acid. The column was washed successively with $2 \mathrm{~mL}$ of $1 \mathrm{M}$ formic acid, $2 \mathrm{~mL}$ of methanol, and $2 \mathrm{~mL}$ of $0.35 \mathrm{M} \mathrm{NH}_{4} \mathrm{OH}$, and the CKs bases, ribosides, and glucosides were eluted with $2 \mathrm{~mL}$ of $0.35 \mathrm{M} \mathrm{NH}_{4} \mathrm{OH}$ in $60 \%$ (v/v) methanol. This eluted fraction was evaporated to dryness in the vortex evaporator and redissolved in $250 \mu \mathrm{L}$ of methanol:0.05\% formic acid (40:60, v/v). The solution was centrifuged at $8,000 g_{n}$ for $5 \mathrm{~min}$ before its injection in the LC/MS/MS system. The CKs were quantified by HPLC (2795 Alliance HT; Waters) linked to a 3200 Q TRAP LC/MS/MS System (Applied Biosystems/MDS Sciex) equipped with an electrospray interface, using an reverse-phase column (Tracer Excel 120 ODSA $3 \mu \mathrm{m}, 100 \times 4.6 \mathrm{~mm}$; Teknokroma, Barcelona, Spain). A linear gradient of methanol (A) and $0.05 \%$ formic acid in water (B) was used: $35 \%$ to $95 \%$ $\mathrm{A}$ in $11 \mathrm{~min}, 95 \% \mathrm{~A}$ for $3 \mathrm{~min}$ and $95 \%$ to $35 \% \mathrm{~A}$ in $1 \mathrm{~min}$, followed by a stabilization time of $5 \mathrm{~min}$. The flow rate was $0.25 \mathrm{~mL} \cdot \mathrm{min}^{-1}$, the injection volume was $40 \mu \mathrm{L}$, and the column and sample temperatures were 30 and $20{ }^{\circ} \mathrm{C}$, respectively. Detection and quantification were performed by MRM in the positive-ion mode, employing multilevel calibration curves with deuterated $\mathrm{CKs}$ as internal standards. Compounds dependents parameters are listed in Table 3. The source parameters are: curtain gas: $172.37 \mathrm{kPa}, \mathrm{GS} 1: 344.74 \mathrm{kPa}, \mathrm{GS} 2$ : $413.69 \mathrm{kPa}$, ion spray voltage: $5000 \mathrm{~V}$, and temperature: $600^{\circ} \mathrm{C}$. Data samples were processed using Analyst 1.4.2 software (Applied Biosystems/MDS Sciex).

Analysis of NO. Cucumber leaves and roots were harvested and washed with deionized water, removing the excess humid-

Table 3. Optimal parameters for the multiple reaction monitoring detection of cytokinins used in the HPLC mass spectrometry analysis of Fe-starved $(0 \mu \mathrm{M})$ and Fe-sufficient $(40 \mu \mathrm{M})$ cucumber plants.

\begin{tabular}{lccccccc}
\hline & & & \multicolumn{5}{c}{ Ionization and collision parameters $^{\mathrm{y}}$} \\
\cline { 4 - 7 } Compound $^{z}$ & Transition & Dwell $(\mathrm{ms})$ & DP & EP & CEP & CE & CXP \\
\hline $\mathrm{Z}$ & $220.3>136.2$ & 150 & 36 & 3.5 & 16 & 25 & 4 \\
$\mathrm{DHZ}$ & $222.3>136.2$ & 150 & 41 & 3.0 & 16 & 29 & 4 \\
tZR & $352.3>220.2$ & 150 & 46 & 4.5 & 19 & 25 & 4 \\
$\mathrm{cZR}$ & $352.3>220.2$ & 150 & 46 & 4.5 & 19 & 25 & 4 \\
$\mathrm{DHZR}$ & $354.3>222.2$ & 150 & 36 & 4.0 & 19 & 27 & 4 \\
$\mathrm{iP}$ & $204.3>136.2$ & 150 & 31 & 4.0 & 14 & 21 & 4 \\
$\mathrm{iPR}$ & $336.2>204.2$ & 150 & 36 & 4.0 & 18 & 23 & 4 \\
{$\left[{ }^{2} \mathrm{H}_{5}\right] \mathrm{tZ}$} & $225.1>136.9$ & 150 & 31 & 3.5 & 16 & 27 & 4 \\
{$\left[{ }^{2} \mathrm{H}_{5}\right] \mathrm{tZR}$} & $357.1>225.2$ & 150 & 31 & 6.0 & 20 & 25 & 4 \\
{$\left[{ }^{2} \mathrm{H}_{6}\right] \mathrm{iP}$} & $210.2>136.9$ & 150 & 31 & 5.0 & 14 & 21 & 4 \\
{$\left[{ }^{2} \mathrm{H}_{6}\right] \mathrm{iPR}$} & $342.2>210.2$ & 150 & 61 & 4.5 & 20 & 25 & 4 \\
\hline
\end{tabular}

${ }^{\mathrm{z}} \mathrm{Z}=$ trans-zeatin, $\mathrm{DHZ}=$ dihydrozeatin, $\mathrm{tZR}=$ trans-zeatin riboside, $\mathrm{cZR}=$ cis-zeatin riboside, $\mathrm{DHZR}=$ dihydrozeatin riboside, $\mathrm{iP}=$ isopentenyladenine, $\mathrm{iPR}=$ isopentenyladenosine, $\left[{ }^{2} \mathrm{H}_{5}\right] \mathrm{tZ}=$ $\left[{ }^{2} \mathrm{H}_{5}\right]$ trans-zeatin, $\left[{ }^{2} \mathrm{H}_{5}\right]$ tZR $=\left[{ }^{2} \mathrm{H}_{5}\right]$ trans-zeatin riboside, $\left[{ }^{2} \mathrm{H}_{6}\right]$ iP $=\left[{ }^{2} \mathrm{H}_{6}\right] \mathrm{N}^{6}$-isopentenyladenine, $\left[{ }^{2} \mathrm{H}_{6}\right]$ iPR $=\left[{ }^{2} \mathrm{H}_{6}\right] \mathrm{N}^{6}$-isopentenyladenosine.

${ }^{\mathrm{y}} \mathrm{DP}=$ declustering potential, $\mathrm{EP}=$ entrance energy, $\mathrm{CEP}=$ collision cell entrance potential, $\mathrm{CE}=$ collision energy, CXP $=$ collision cell exit potential. ity before measuring the NO. Cotyledons and stems were not used in this measure. Samples were ground with mortar and pestle in liquid nitrogen. Then, $0.5 \mathrm{~g}$ of ground samples (fresh weight based) were mixed with $2 \mathrm{~mL}$ of $40 \mathrm{~mm}$ HEPES buffer, $\mathrm{pH} 7.2$, to achieve a 1:4 (w/v) proportion between sample and buffer (Corpas et al., 2004). Samples were kept on ice during the procedure to prevent sample degradation. The homogenized ple was filtered using Miracloth paper, and the filtered After that, $340 \mu \mathrm{L}$ of supernatant and $10 \mu \mathrm{L}$ of a $350 \mu \mathrm{M}$ DAF-2 solution were then added into each well of a black 96-well plate where the reaction took place). The plates were incubated for 30 $25^{\circ} \mathrm{C}$ before reading the fluorescence intensities using (Tecan Group, Männedorf, Switzerland). A reference calibration curve was established using fluorescein at different concentras. This curve provides reference intensities values to com(NC) with no DAF-2 were also used. The final result was xpressed as fluorescence units per gram of fresh weight (FW).

STATISTICAL ANALYSIS. Four replications with three plants per replication were employed for the different analytical determinations described above. Significant differences $(P<0.05)$ among treatments were calculated by using one-way analysis of variance (ANOVA) and the Fisher's post hoc test. Statistical alysis of relative gene expression results was assessed using $\mathrm{P}-$ pairwise fixed reallocation randomization test.

\section{Results}

FE STARVATION AFFECTED DIFFERENTLY THE GENE EXPRESSION AND THE ACTIVITY OF THE MAIN PROTEINS INVOLVED IN THE PHYSIOLOGICAL Fe STRESS RoOT RESPONSES. A clear increase in the root $\mathrm{Fe}$ (III)-chelate reductase activity was observed $1 \mathrm{~d}$ from onset of treatments for Fe-starved plants with respect to $\mathrm{Fe}$ (Fig. 1A). This increase was maintained along the experiment, although a decrease in intensity was noted at days 9 and 11. These results are in accordance with the expression of the gene that encodes the root $\mathrm{Fe}$ (III)-chelate reductase in cucumber (CsFRO1). Expression of this gene showed a significant increase after $1 \mathrm{~d}$ of Fe starvation (Fig. 1B). This increase was sustained along the time of the study, showing notable increases after 3,5, 9, and $11 \mathrm{~d}$ from the onset of treatments. In relation to the gene encoding the $\mathrm{Fe}(\mathrm{II})$-transporter (CsIRT1), it presented a significant increase after $1 \mathrm{~d}$ of Fe deficiency with maximum values at the end of the experiment (Fig. 1B).

The results concerning $\mathrm{H}^{+}$ATPase activity and gene expression were different from those described above for $\mathrm{Fe}$ (III)-chelate reductase and $\mathrm{Fe}(\mathrm{II})$-transporter. Two $\mathrm{H}^{+}$ATPase genes have been isolated from cucumber roots: $C s H A 1$ and CsHA2. CsHA1 is upregulated, while $\mathrm{CsHA2}$ is constitutively expressed 
and did not respond to Fe deficiency (Santi et al., 2005). Thus, although a significant and time-sustained increase in the gene expression of the CSHAl isoform was observed from the first day of the onset of treatments in Fe-starved plants (Fig. 2A), the $\mathrm{H}^{+}$-ATPase activity only experienced a significant increase after 5 and $9 \mathrm{~d}$, reflected in a significant decrease of the $\mathrm{pH}$ of the nutrient solution at $11 \mathrm{~d}$ (Fig. 2, B and C). Thus, whereas the activation of CsHAl expression in Festarved cucumber plants was expressed similarly to CsFROI and CsIRTI expression, the activity of the $\mathrm{H}^{+}$-ATPase enzyme was differently enhanced over time. These results indicate that the transcriptional control of $\mathrm{H}^{+}$-ATPase (CsHAl isoform) gene might be coregulated with that of $\mathrm{Fe}$ (III)-chelate reductase (CsFROI) and $\mathrm{Fe}(\mathrm{II})$-transporter (CsIRT1) genes. However, the regulation at the enzyme activity level of $\mathrm{H}^{+}$-ATPase is expressed differently from that of $\mathrm{Fe}$ (III)-chelate reductase and, probably, Fe(II)-transporter, in the root. These results suggest the possible involvement of different, although prob-
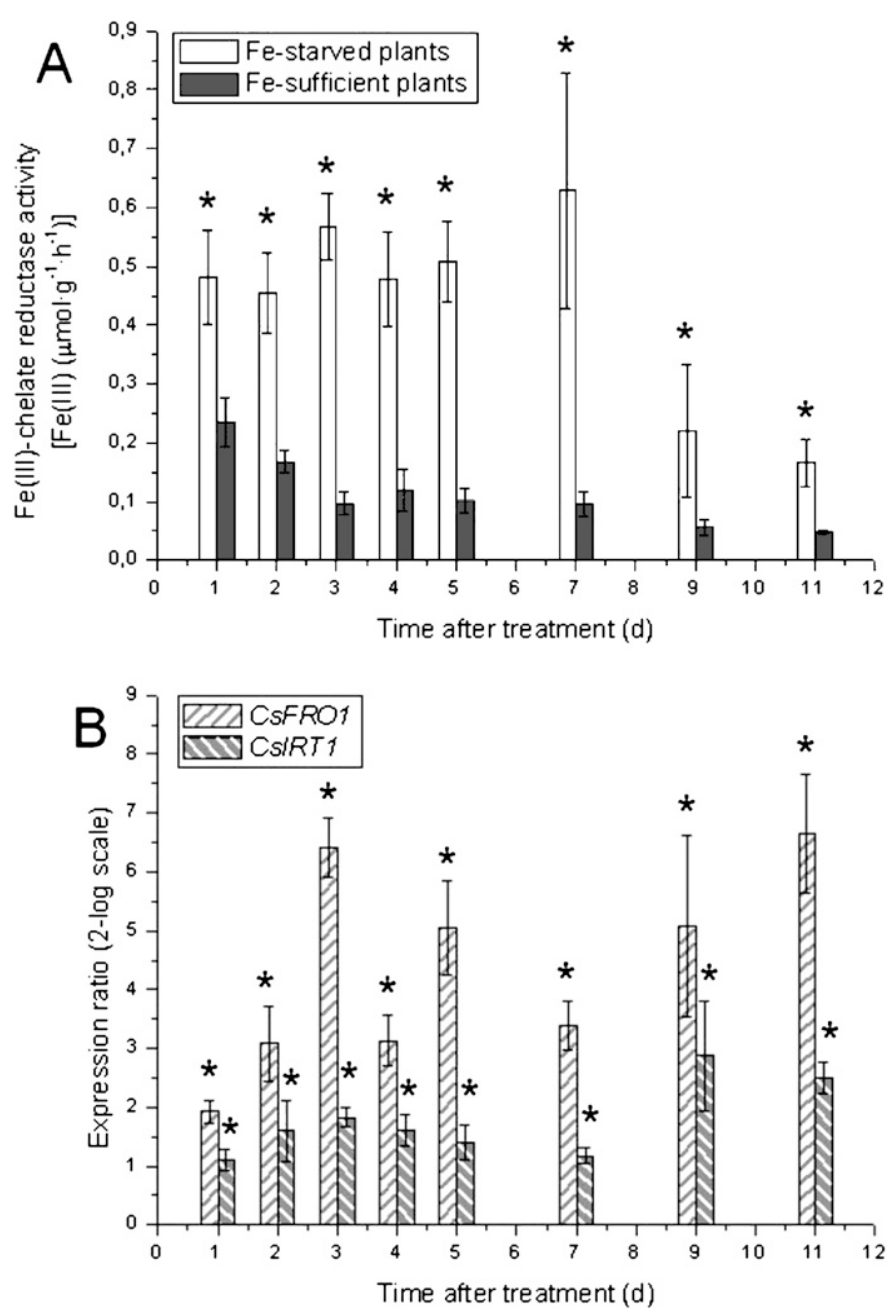

Fig. 1. (A) Fe(III)-chelate reductase activity in roots of Fe-starved (- $\square$-) and Fesufficient (-口-) cucumber plants. (B) Effects of Fe deficiency on CsFROI (white striped bars) and CSIRTI (grey striped bars) gene expression in roots of cucumber plants (mean $\pm \mathrm{SE}, \mathrm{n}=4$ ). Asterisks indicate the presence of significant differences for $P<0.05$ between $+\mathrm{Fe}(40 \mu \mathrm{M})$ and $-\mathrm{Fe}(0 \mu \mathrm{M})$ treatments based on one-way ANOVA and Fisher's post hoc test. Statistical analysis of relative gene expression results was assessed using $\mathrm{P}$-pairwise fixed reallocation randomization test. ably interrelated, regulatory systems for the transcriptional and post-transcriptional expression of the main physiological $\mathrm{Fe}$ stress root responses.

It is interesting to note that $\mathrm{Fe}$-starved plants presented a slight but not significant decrease in the leaf concentration of chlorophyll in comparison with Fe-sufficient plants (Fig. 3).

FE STARVATION AFFECTED DIFFERENTLY THE GENE EXPRESSION AND THE ACTIVITY OF THE MAIN PROTEINS INVOLVED IN THE PHYSIOLOGICAL Fe STRESS ROOT RESPONSES. The results show that there was a slight nonsignificant increase in ethylene production in the root after $1 \mathrm{~d}$ from the onset of Fe starvation in Fe-starved plants with respect to Fe-sufficient plants (Fig. 4). However, after $2 \mathrm{~d}$, the increase in root ethylene production in Fe-starved plants was very clear and significant when compared with Fe-sufficient plants (Fig. 4). These results were systematically obtained in three independent experiments (data not shown).

Regarding IAA, a clear and sustained increase in its shoot concentration in Fe-starved plants with respect to Fe-sufficient plants was observed. This increase was slight after 1, 2, and $3 \mathrm{~d}$, but very significant and sustained after $4 \mathrm{~d}$ (Fig. 5A). These changes in the shoots were correlated with a concomitant increase in the roots of Fe-starved plants after 1 and $2 \mathrm{~d}$ (Fig. 5B).

Fe starvation also affected ABA and NO concentrations. The results show that the variation pattern of ABA concentration in shoot and root changed significantly depending on Fe nutrition status (Fig. 6). Thus, whereas ABA concentration in the shoot of Fe-starved plants experienced a slight but significant decrease after 1, 4, 7, 9, and $11 \mathrm{~d}$ of Fe starvation (Fig. 6A), ABA root concentration presented a significant increase after 1,2 , and $3 \mathrm{~d}$ (Fig. 6B).

The results concerning NO concentration in shoots and roots (Fig. 7) also showed significant changes depending on Fe plant status. Thus, after $1 \mathrm{~d}$ of $\mathrm{Fe}$ starvation, a significant and transient increase in the root NO concentration (Fig. 7B) was noted in Fe-starved plants when compared with Fe-sufficient ones, which corresponded to a concomitant decrease in the shoot (Fig. 7A).

Finally, regarding the variation pattern of the different CKs studied under Fe starvation, the results obtained show that most of them tended to decrease in Fe-starved plants. These changes, along with those described above for IAA, caused significant decreases in auxin:cytokinin ratio values in the roots and shoots in Fe-starved plants when compared with $\mathrm{Fe}$-sufficient plants (data not shown). Thus, whereas significant differences in $\mathrm{Z}$ concentration between treatments were not observed in roots or shoots (data not shown), the concentration of DHZR in the roots of Fe-starved plants was lower than that in $\mathrm{Fe}$-sufficient plant roots after $3 \mathrm{~d}$ of Fe deficiency (Fig. 8B). These changes in root DHZR concentrations with Fe starvation were not accompanied by differences in the shoot (Fig. 8A). In the case of c-ZR, a lower concentration after 1, 2, 5, 7, and $11 \mathrm{~d}$ of Fe starvation in the shoots of $\mathrm{Fe}$-starved plants was observed in comparison with Fe-sufficient plants (Fig. 9A), which was associated with higher concentrations in the root after 1 and $2 \mathrm{~d}$, followed by lower concentrations after 3 and $11 \mathrm{~d}$ (Fig. 9B). However, the concentration of $\mathrm{t}$-ZR did not present any significant differences between treatments (data not shown). Finally, whereas no significant differences between treatments were observed for iPR (data not shown), the root concentration of iP in Fe-starved plants was lower than that for Fe-sufficient plants after 3 and $11 \mathrm{~d}$ from the onset of Fe-starvation (Fig. 10B). However, in the 

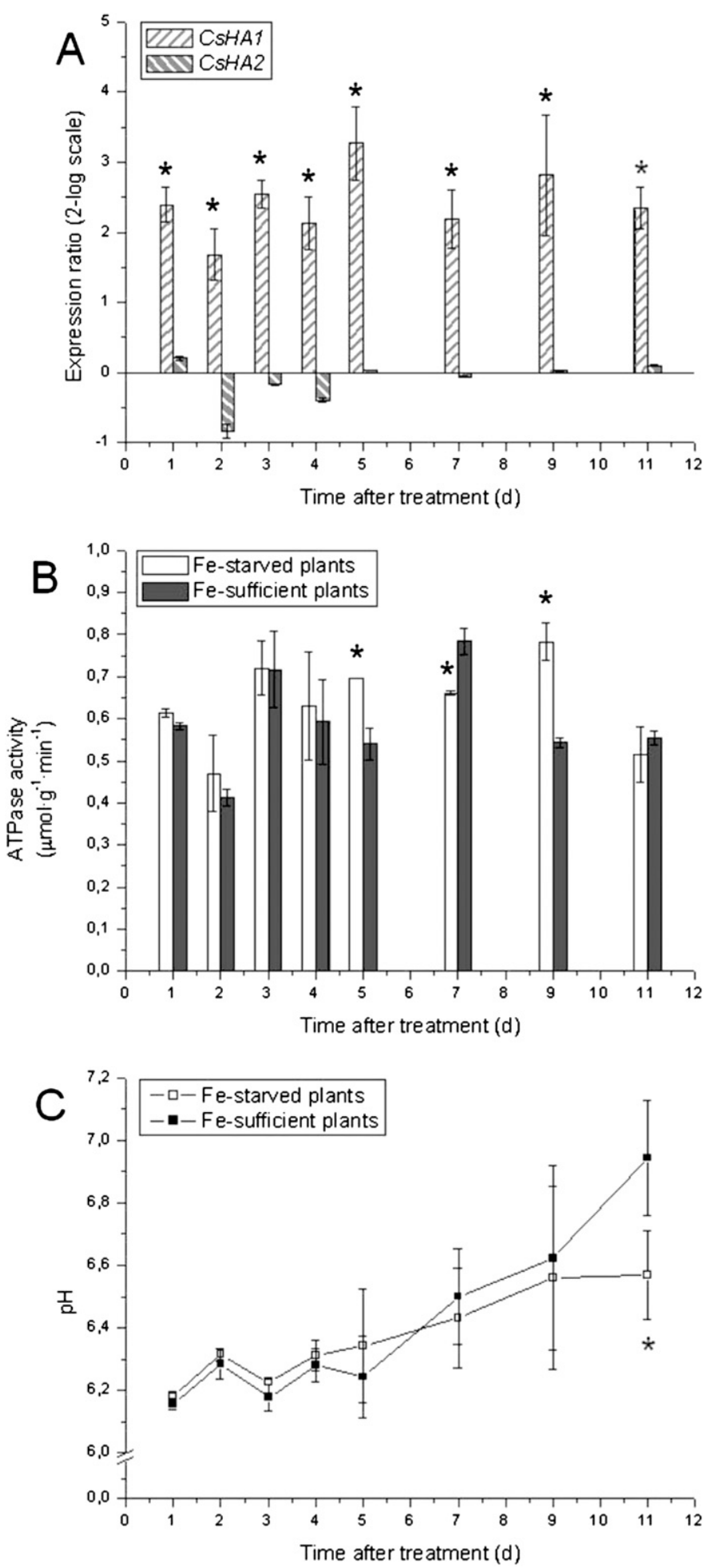

Fig. 2. (A) Effects of Fe deficiency on CsHAl (white striped bars) and CsHA2 (grey striped bars) gene expression in roots of cucumber plants. (B) $\mathrm{H}^{+}$-ATPase activity in roots and (C) nutrient solution $\mathrm{pH}$ of Fe-starved (- $\square$-) and $\mathrm{Fe}$-sufficient (- - ) cucumber plants (mean $\pm \mathrm{SE}, \mathrm{n}=4$ ). Asterisks indicate the presence of significant differences for $P<0.05$ between $+\mathrm{Fe}(40 \mu \mathrm{M})$ and $-\mathrm{Fe}(0 \mu \mathrm{M})$ treatments based on one-way ANOVA and Fisher's post hoc test. Statistical analysis of relative gene expression results was assessed using P-pairwise fixed reallocation randomization test.

shoot, there were not significant differences between treatments (Fig. 10A).

Regarding the gibberellins studied (GA3, GA4, and GA7), their concentrations were below the detection limits of our technique.

\section{Discussion}

There is in the literature experimental evidence showing that the regulation of the main Fe deficiency root responses involves different and coregulated pathways at the local level (root region) and the systemic level (shoot to root region) (Curie and Briat, 2003; Schmidt, 2006; Vert et al., 2003). This coregulated system depends on the Fe status of the plant (Curie and Briat, 2003; Schmidt, 2006; Vert et al., 2003). Some authors have proposed specific hormones as candidates to control the expression of $\mathrm{Fe}$ deficiency responses: ethylene (Lucena et al., 2006; Romera et al., 2006), IAA (Landsberg, 1981a, 1981b, 1981c, 1984; Römheld and Marschner, 1986), and NO (Graziano and Lamattina, 2007). These studies have been fundamentally based on pharmacological approaches employing specific functional inhibitors or precursors. However, other studies employing different strategies (plant mutants and time-course patterns) questioned these conclusions ( $\mathrm{Li}$ and $\mathrm{Li}, 2004$; Schmidt et al., 2000b). In this context, a complementary study dealing with the relationship between the timecourse expression of the main $\mathrm{Fe}-$ regulated genes in the roots and the hormonal balance in the whole plant (roots and shoots) might aid in clarifying this controversy.

A number of studies have reported that Fe deficiency is associated with an increment in the root production of ethylene (Romera et al., 2006). Further studies involving ethylene precursors and different inhibitors of ethylene synthesis or action indicated that ethylene could be directly involved in the regulation of the transcriptional expression of the main genes involved in Fe deficiency stress responses of Strategy I plants (Lucena et al., 2006). However, the results reported by $\mathrm{Li}$ and $\mathrm{Li}$ (2004) indicated that the increase in ethylene root production linked to Fe deficiency was not timely synchronized with the expression of the root $\mathrm{Fe}(\mathrm{III})$-chelate reductase activity, which presented significant activity before the ethylene root production increase. These results suggest that the variation in ethylene root production in Fe-deficient plants could be a consequence but not the cause of the 


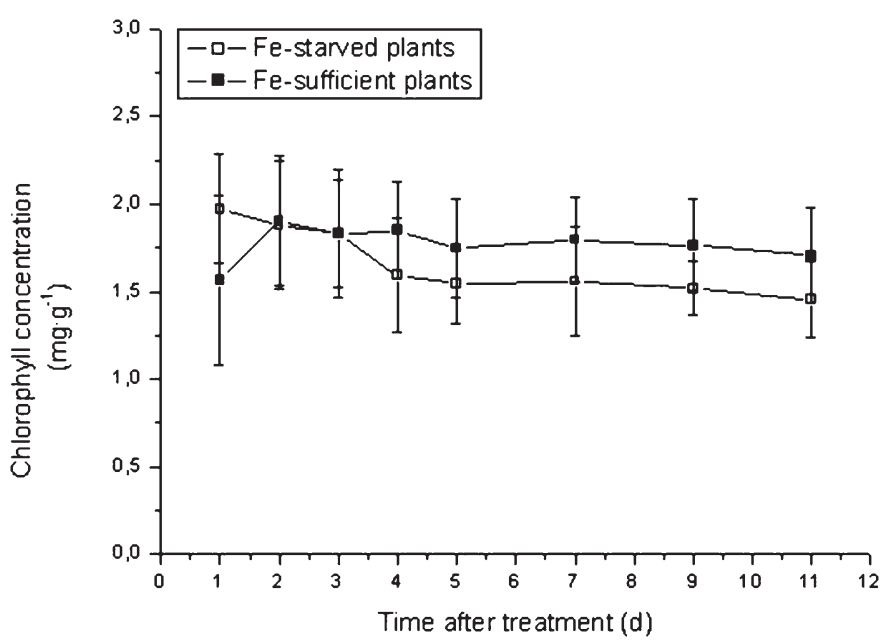

Fig. 3. Chlorophyll concentration in the newly formed leaves of Fe-starved (- $\square$-) and Fe-sufficient (-口-) cucumber plants (mean $\pm \mathrm{SE}, \mathrm{n}=4$ ). Asterisks indicate the presence of significant differences for $P<0.05$ between $+\mathrm{Fe}(40 \mu \mathrm{M})$ and $-\mathrm{Fe}(0 \mu \mathrm{M})$ treatments based on one-way ANOVA and Fisher's post hoc test.

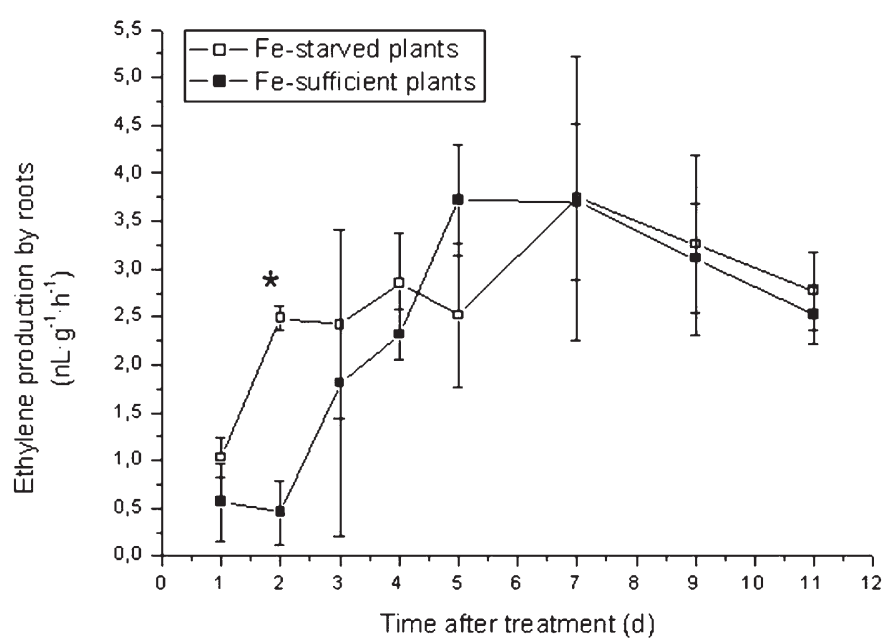

Fig. 4. Ethylene released by roots of Fe-starved (- $\square-$ ) and Fe-sufficient (- $\square-$ ) cucumber plants (mean $\pm \mathrm{SE}, \mathrm{n}=4$ ). Asterisks indicate the presence of significant differences for $P<0.05$ between $+\mathrm{Fe}(40 \mu \mathrm{M})$ and $-\mathrm{Fe}(0 \mu \mathrm{M})$ treatments based on one-way ANOVA and Fisher's post hoc test.

activation of root response. This conclusion agrees with other results obtained in experiments carried out with arabidopsis mutants insensitive or oversensitive to different hormones, including ethylene (Schmidt et al., 2000b). The results obtained in the present study indicate that the increase in ethylene root production in Fe-starved plants (Fig. 4) was not clearly timely synchronized with the transcriptional expression of the genes encoding the $\mathrm{Fe}(\mathrm{III})$-chelate reductase (CsFRO1), the $\mathrm{Fe}(\mathrm{II})$ root transporter (CSIRTI), and the $\mathrm{H}^{+}$-ATPase (CsHA1), or with the activity of the $\mathrm{Fe}(\mathrm{III})$-chelate reductase (Figs. 1 and 2A). Thus, a slight, but not significant, increase in ethylene root production in Fe-starved plants was timely synchronized with the expression of $\mathrm{Fe}$ stress root responses. This small increase in ethylene root production was repeated in different independent experiments, but it was not significant due to data variability. Therefore, it is possible that this slight increase in ethylene root production is involved in the transcriptional control of the main
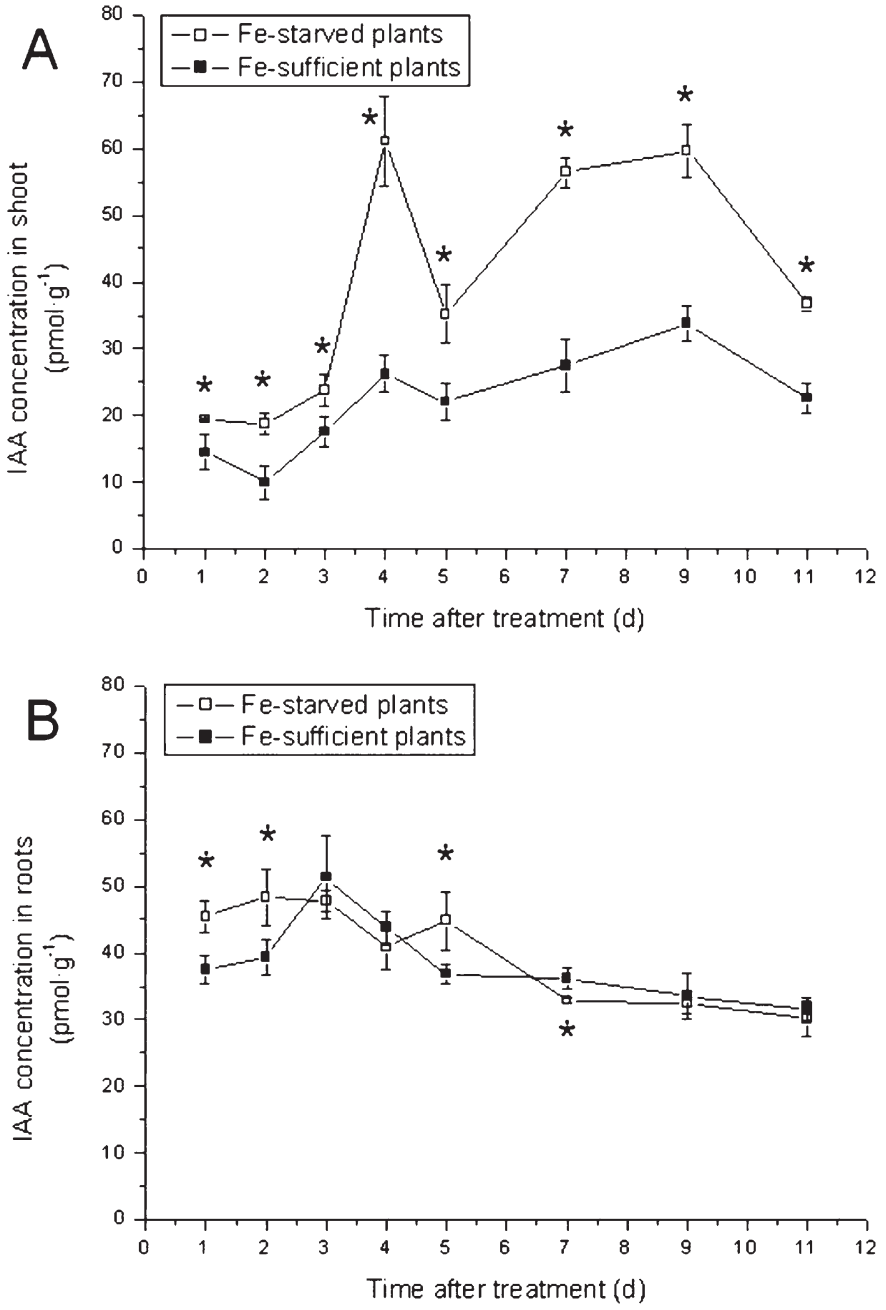

Fig. 5. Effects of Fe deficiency on indol-3-acetic acid (IAA) concentration in cucumber plants. (A) IAA concentration in shoot of Fe-starved plants (- $\square-$-) compared with Fe-sufficient ones (-口-). (B) IAA concentration in roots of Festarved (- $\square$-) and Fe-sufficient (-口-) plants (mean \pm SE, $n=4)$. Asterisks indicate the presence of significant differences for $P<0.05$ between $+\mathrm{Fe}$ ( 40 $\mu \mathrm{M})$ and $-\mathrm{Fe}(0 \mu \mathrm{M})$ treatments based on one-way ANOVA and Fisher's post hoc test.

physiological root responses, in agreement with the results reported by Lucena et al. (2006). However, it is noteworthy that Fe-sufficient plants also presented an increase in ethylene production up to the levels of Fe-starved plants, but $1 \mathrm{~d}$ later. This fact suggests that Fe starvation might accelerate a natural process involving root ethylene production, which also occurs in Fe-sufficient plants. In any case, studies carried out using Fesufficient plants indicated that the action of ethylene might be necessary but not enough to activate $\mathrm{Fe}$ stress physiological root responses (Lucena et al., 2006; Romera et al., 2006). In this context, studies on the transcriptional and post-transcriptional expression of the main physiological root responses to $\mathrm{Fe}$ deficiency in arabidopsis mutants insensitive to ethylene would be of great interest. In this sense, recent studies indicate that $F R O 2$ and $I R T I$ expression is upregulated under conditions of Fe deficiency in several arabidopsis ethylene-insensitive mutants (ert1, ein2, and ein3eill) (García et al., 2007). At first, these results could suggest that ethylene is not involved in the process. However, the application of ethylene precursors was 

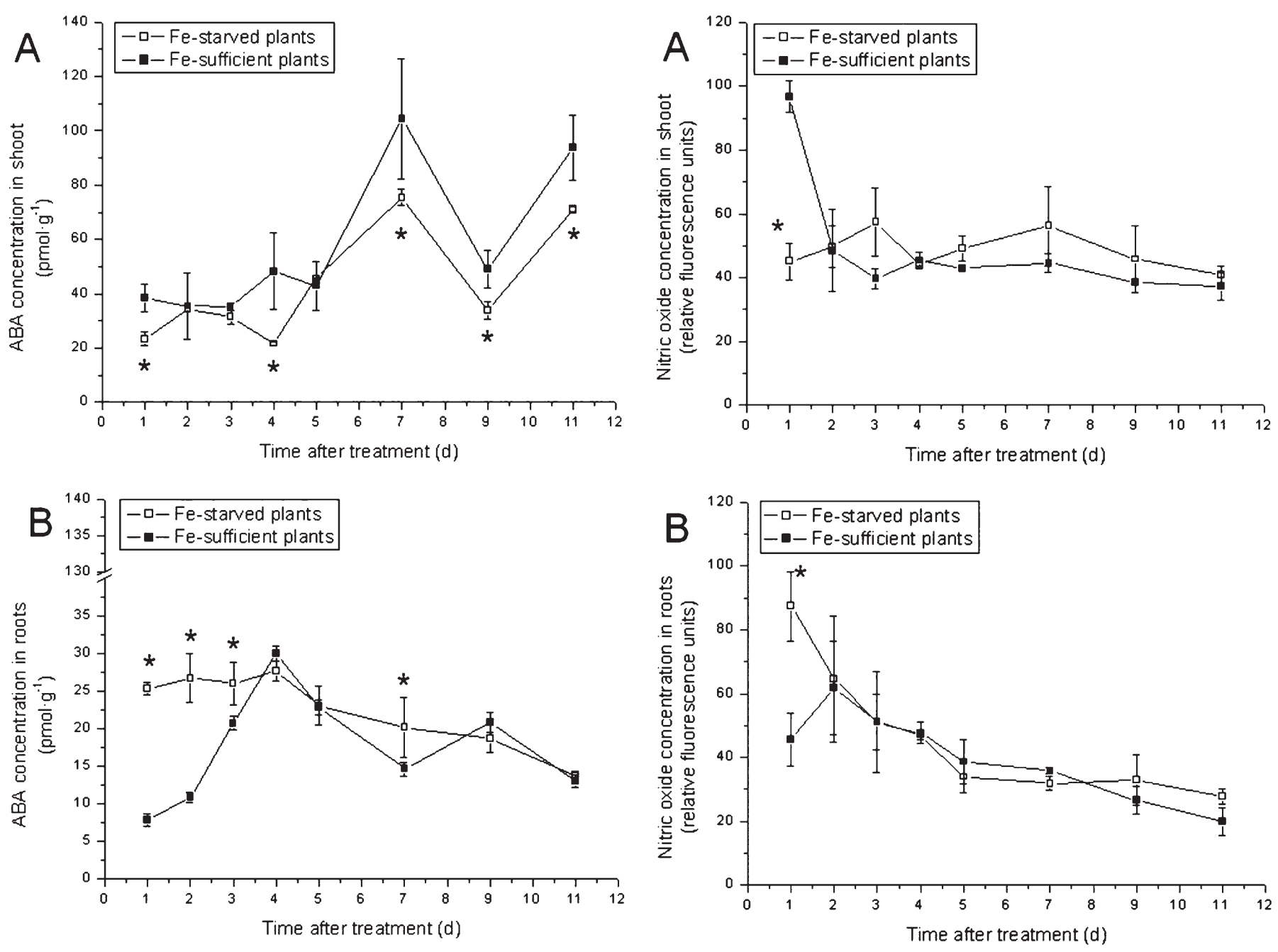

Fig. 6. Effects of iron deficiency on abscisic acid (ABA) concentration in cucumber plants. (A) ABA concentration in shoot of Fe-starved plants (- $\square$-) compared with Fe-sufficient ones (- - -). (B) ABA concentration in roots of Fe-starved (- $\square$-) and Fe-sufficient (- - -) plants (mean $\pm \mathrm{SE}, \mathrm{n}=4$ ). Asterisks indicate the presence of significant differences for $P<0.05$ between $+\mathrm{Fe}(40$ $\mu \mathrm{M})$ and $-\mathrm{Fe}(0 \mu \mathrm{M})$ treatments based on one-way ANOVA and Fisher's post hoc test.

associated with the upregulation of both genes, whereas the application of ethylene inhibitors was associated with a downregulation of these genes (García et al., 2007), thus indicating that ethylene could be involved in their transcriptional control, but through a singular and specific pathway. Likewise, a possible role of ethylene through changes in its local concentration, in specific root areas or in the cell sensitivity to ethylene action, cannot be ruled out.

The results obtained in this work also showed that $\mathrm{Fe}$ starvation was associated with significant increases in the IAA concentration in roots and, mainly, in shoots when compared with plants receiving Fe (Fig. 5). The effects of Fe starvation on IAA root concentration were observed on the same day as those related to root gene expression and enzyme activities, although it was transient and disappeared after $2 \mathrm{~d}$. The effects observed on the shoot IAA concentration, however, were sustained and well correlated to those related to root gene expression and enzyme activities (Figs. 1 and 2). These results are compatible with a possible role of IAA in the regulation of

Fig. 7. Effects of Fe deficiency on nitric oxide concentration in shoot (A) and roots (B) of Fe-starved (- $\square$-) and Fe-sufficient (- - -) cucumber plants (mean \pm $\mathrm{SE}, \mathrm{n}=4)$. Asterisks indicate the presence of significant differences for $P<$ 0.05 between $+\mathrm{Fe}(40 \mu \mathrm{M})$ and $-\mathrm{Fe}(0 \mu \mathrm{M})$ treatments based on one-way ANOVA and Fisher's post hoc test.

the plant responses to Fe deficiency at transcriptional and enzyme activity levels. Some authors have also suggested that the systemic shoot to root regulation of the main $\mathrm{Fe}$ stress root responses may be mediated by IAA (Landsberg, 1981a, 1981b, 1981c, 1984; Römheld and Marschner, 1986). In this way, some studies involving functional inhibitors of IAA polar transport and activity and the decapitation of plant shoot apex showed that IAA might be involved in the expression of morphological and physiological Fe stress root responses (De la Guardia et al., 1988; Landsberg, 1981a, 1981c, 1984; Li et al., 2000). Likewise, as in the case of ethylene, a number of studies using auxin compounds indicated that they were able to induce the main morphological root changes (subapical swelling, transfer cells, and root hairs) even in Fe-sufficient plants (Landsberg, 1981b, 1984; Schmidt and Bartels, 1996; Schmidt et al., 2000a). In this sense, some studies indicate that IAA and ethylene could act in a coordinated way in the regulation of the root morphological responses to Fe deficiency (Romera et al., 2006). However, as in the case of ethylene, the study carried out by Schmidt et al. (2000b) using arabidopsis mutants insensitive to IAA showed that the action of this hormone probably is not strictly necessary 

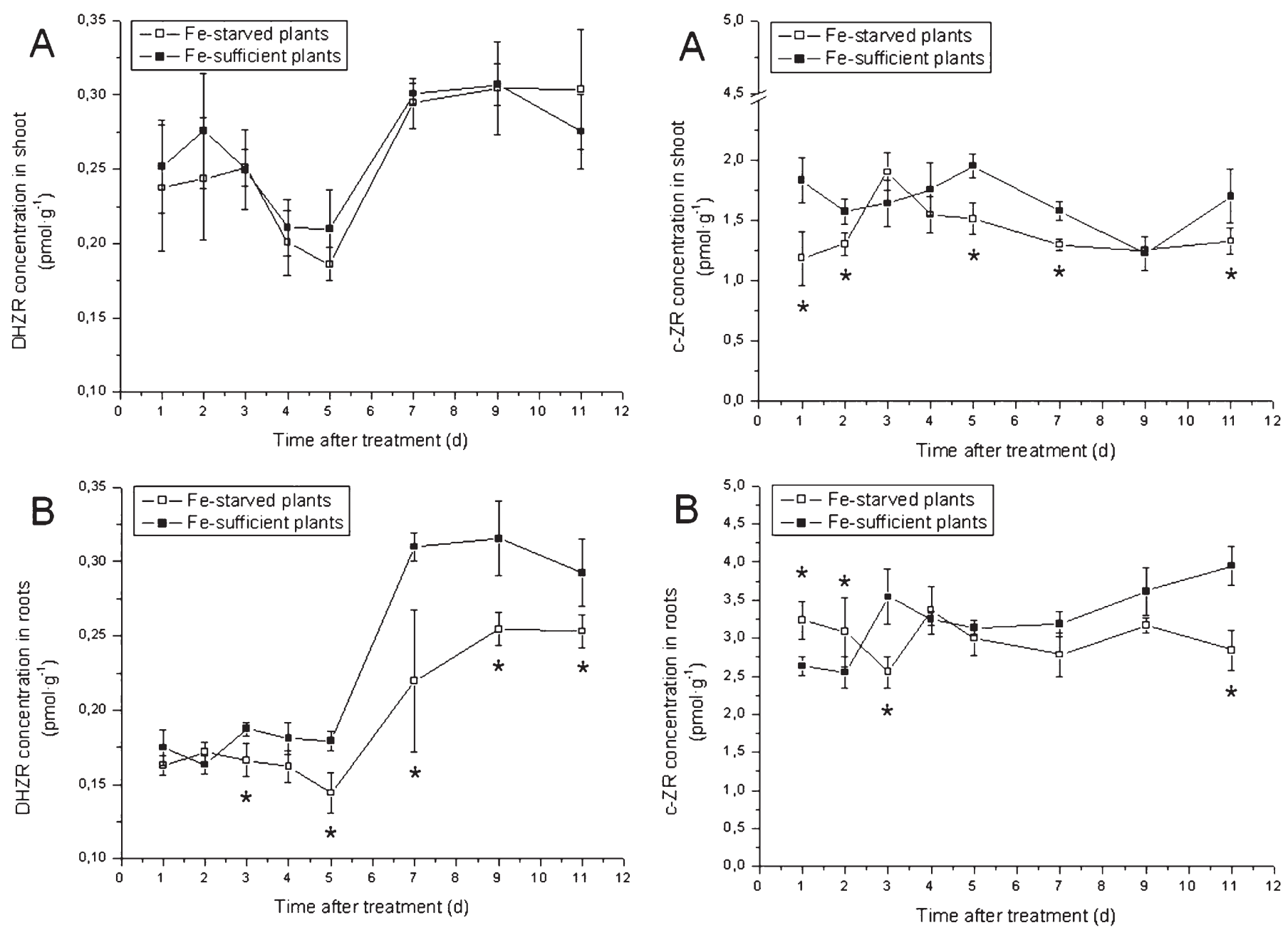

Fig. 8. Effects of Fe deficiency on dihydrozeatin riboside (DHZR) concentration in shoot (A) and roots (B) of Fe-starved (- $\square$-) and Fe-sufficient (- $\square-$ ) cucumber plants (mean $\pm \mathrm{SE}, \mathrm{n}=4$ ). Asterisks indicate the presence of significant differences for $P<0.05$ between $+\mathrm{Fe}(40 \mu \mathrm{M})$ and $-\mathrm{Fe}(0 \mu \mathrm{M})$ treatments based on one-way ANOVA and Fisher's post hoc test.

for the upregulation of the Fe(III)-chelate reductase. However, the results obtained by Schmidt et al. (2000b), and also the results obtained in this study, are compatible with an involvement of IAA in the regulation of some of the Fe stress root responses, at least at transcriptional level. In this sense, the IAA capacity to activate $\mathrm{Fe}$ stress root physiological responses in $\mathrm{Fe}$ sufficient plants, although controversial, cannot be ruled out. Whereas Schmidt and coworkers did not observe an increase in root $\mathrm{Fe}(\mathrm{III})$-chelate reductase activity (Schmidt, 1994) or rhizosphere acidification (Schmidt et al., 2003) upon 2,4-D application to Fe-sufficient plantago (Plantago lanceolata L.) and tomato (Solanum lycopersicum L.) plants, respectively, $\mathrm{Li}$ and $\mathrm{Li}$ (2004) noted that indol-3-butyric acid (IBA) caused an increase in root $\mathrm{Fe}(\mathrm{III})$-chelate reductase activity in $\mathrm{Fe}$ sufficient cucumber and bean (Phaseolus vulgaris L.) plants.

It was interesting to note the significant increase in shoot IAA concentration upon $\mathrm{Fe}$ starvation (Fig. 5). This fact supports the view that the increase in IAA root concentration observed under Fe deficiency might be directly linked to the transport to the root of IAA synthesized in the shoot (polar auxin transport) as proposed in previous studies (De la Guardia et al., 1988; Han et al., 2005; Landsberg, 1981a, 1981c, 1984;

Fig. 9. Effects of Fe deficiency on cis-zeatin riboside (c-ZR) concentration in shoot (A) and roots (B) of Fe-starved (- $\square$-) and Fe-sufficient (- $\square$-) cucumber plants (mean $\pm \mathrm{SE}, \mathrm{n}=4$ ). An asterisk indicates the presence of significant differences for $P<0.05$ between $+\mathrm{Fe}(40 \mu \mathrm{M})$ and $-\mathrm{Fe}(0 \mu \mathrm{M})$ treatments based on one-way ANOVA and Fisher's post hoc test.

Li et al., 2000). Likewise, these results also suggest that IAA could be involved in the high efficiency of this cucumber cultivar to use the Fe available in the shoot (Bacaicoa and García-Mina, 2009). The possible enhanced shoot to root transport of IAA under conditions of Fe deficiency also support the hypothesis of a possible role of IAA in the systemic control of Fe stress root responses. In this context, further investigation into the transcriptional expression of the main Fe stress root responses involving arabidopsis IAA-insensitive mutants and functional IAA inhibitors is of great interest.

The pattern of variations found on the concentrations of $\mathrm{ABA}$ and $\mathrm{NO}$ in roots and shoots under Fe deficiency (Figs. 6 and 7) was also interesting. In both cases, the concentrations of these plant regulators in the root of Fe-starved plants were lower than those for Fe-sufficient plants, but these effects were transient and only expressed at the beginning of Fe starvation. In the case of ABA, these differences were clear for the first $3 \mathrm{~d}$ after Fe starvation. In the case of NO, they were expressed only the first day. Regarding the shoot, the effect of Fe starvation on ABA concentration was less clear, although it presented a tendency to decrease with respect to Fe-sufficient plants. In 

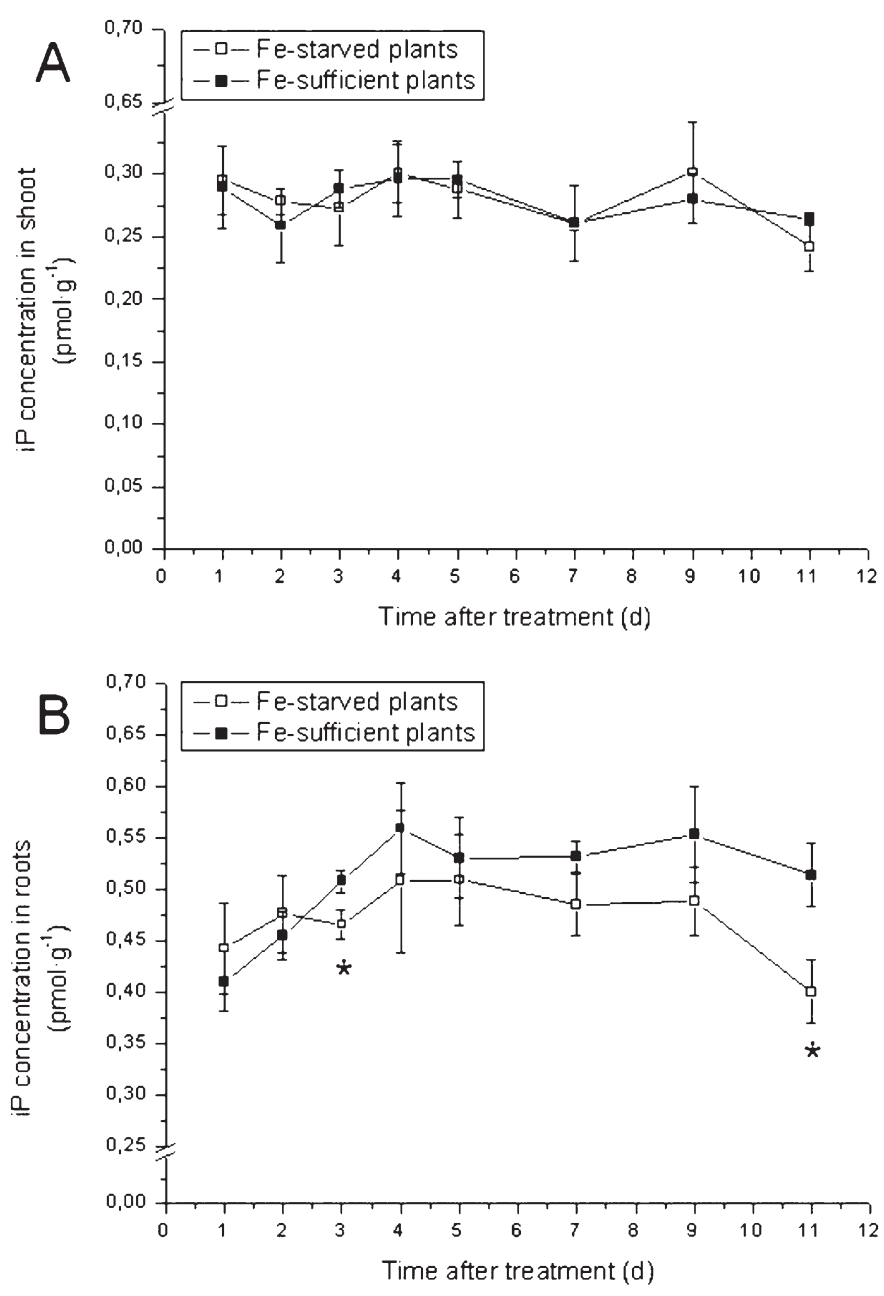

Fig. 10. Effects of Fe deficiency on isopentenyladenine (iP) concentration in shoot (A) and roots (B) of Fe-starved (- $\square$-) and Fe-sufficient (- $\square$-) cucumber plants (mean $\pm \mathrm{SE}, \mathrm{n}=4)$. An asterisk indicates the presence of significant differences for $P<0.05$ between $+\mathrm{Fe}(40 \mu \mathrm{M})$ and $-\mathrm{Fe}(0 \mu \mathrm{M})$ treatments based on one-way ANOVA and Fisher's post hoc test.

the case of $\mathrm{NO}$, its concentration in the shoot of Fe-starved plants was lower than that of Fe-sufficient ones at the first day from the onset of $\mathrm{Fe}$ starvation. The results concerning ABA and NO are compatible with an action of these compounds in the regulation of the studied $\mathrm{Fe}$ stress root responses at transcriptional and enzyme activity levels. Recently, Graziano and Lamattina (2007) reported that an accumulation of NO in root tissues was required for the expression of $\mathrm{Fe}(\mathrm{III})$-chelate reductase (LeFROI) and $\mathrm{Fe}(\mathrm{II})$-transporter (LeIRT1) genes. As in the case of ethylene, NO seems to be necessary but not sufficient to induce these genes because its application to Fesufficient plants did not activate them (Graziano and Lamattina, 2007). Regarding ABA, the results of Schmidt et al. (2000b) employing arabidopsis ABA-insensitive mutants indicated that the action of this hormone was not necessary for the enhancement of $\mathrm{Fe}$ (III)-chelate reductase activity under Fe deficiency. However, these results are compatible with a possible action of this compound at transcriptional level. However, as in the case of ethylene, ABA changes in roots and shoots of Fe-starved and -sufficient plants suggest that Fe starvation induces the activation of a natural process involving ABA concentration in roots, which also occurs in Fe-sufficient plants, but later. This fact could be related to Fe root to shoot transport and Fe storage in the shoot (Lobréaux et al., 1993).

Finally, it was also worthy to note the relationship between the development of $\mathrm{Fe}$ starvation and the reduction in the concentration of several CKs in the roots and shoots (Figs. 8-10). However, these effects were expressed one of several days (depending on the CK studied) after the increase in the expression of the studied genes under Fe starvation, thus suggesting that both phenomena may be complementary but not directly causally linked (CKs as regulators of Fe stress root responses under Fe deficiency). These results are in line with those reported by Séguéla et al. (2008) in arabidopsis. These authors observed that several CKs types down-regulated the expression of the Fe(III)-chelate reductase (FRO2), the Fe(II)transporter (IRT1), and the master gene FIT at transcriptional level. However, this action was independent of Fe nutrition status and affected only one specific set of genes regulated by $\mathrm{Fe}$ deficiency. These results suggested that the repressive action of $\mathrm{CKs}$ on some of the physiological Fe deficiency root responses at the transcriptional level is probably mediated by a mechanism different from that involved in their induction. In this context, the reduction in the root and shoot concentration of some CKs observed in our study under conditions of Fe deficiency could favor the expression of Fe stress root responses to Fe starvation.

In summary, the time-course variations of the parameters studied and their relationships in Fe-sufficient and Fe-starved cucumber plants indicate that the transcriptional regulation of the expression of the studied genes (CsFRO1, CsIRT1, and CsHA1) under Fe starvation in cucumber are compatible with the participation of IAA in the regulation of $\mathrm{Fe}$ stress root responses, whereas the results concerning $\mathrm{NO}, \mathrm{ABA}$, and ethylene are less conclusive. Complementarily studies carried out on Fe-sufficient plant models indicated that the presence of ethylene and NO may be necessary but not sufficient for activating Fe stress root responses (Graziano and Lamattina, 2007; Romera et al., 2006). Preliminary studies carried out in our laboratory with ABA in Fe-sufficient cucumber plants suggested the same conclusion for this hormone. In this sense, it is more likely that the role of $\mathrm{ABA}$ and $\mathrm{NO}$ is related to $\mathrm{Fe}$ storage and remobilization within the plant (Lobréaux et al., 1993; Murgia et al., 2002). However, the results obtained concerning IAA, considered together with those reported by other authors in Fe-sufficient plants (Li and Li, 2004), deserve more in-depth studies. Further investigation on the action of this hormone on the transcriptional and post-transcriptional expression of root $\mathrm{Fe}$ stress responses in plant models involving arabidopsis IAA-insensitive and -oversensitive mutants, as well as functional inhibitors of IAA action, would be of great interest.

\section{Literature Cited}

Abadía, J., A. Álvarez-Fernández, A.D. Rombolà, M. Sanz, M. Tagliavini, and A. Abadía. 2004. Technologies for the diagnosis and remediation of Fe deficiency. Soil Sci. Plant Nutr. 50:965-971. Álvarez-Fernández, A., J. Abadía, and A. Abadía. 2006. Iron deficiency, fruit yield and fruit quality, p. 85-101. In: L.L. Barton and J. Abadía (eds.). Iron nutrition in plants and rhizospheric microorganisms. Springer, Dordrecht, The Netherlands.

Bacaicoa, E. and J.M. García-Mina. 2009. Iron efficiency in different cucumber cultivars: The importance of optimizing the use of foliar iron. J. Amer. Soc. Hort. Sci. 134:405-416.

Bradford, M.M. 1976. A rapid and sensitive method for the quantitation of microgram quantities of protein utilizing the principle of protein-dye binding. Anal. Biochem. 72:248-254. 
Briat, J.F. 2008. Iron dynamics in plants, p. 137-180. In: J.C. Kader and M. Delseny (eds.). Advances in botanical research, Vol. 46. Elsevier Academic Press, Amsterdam, The Netherlands.

Corpas, F.J., J.B. Barroso, A. Carreras, M. Quiros, A.M. León, M.C. Romero-Puertas, F.J. Esteban, R. Valderrama, J.M. Palma, L.M. Sandalio, M. Gómez, and L.A. del Río. 2004. Cellular and subcellular localization of endogenous nitric oxide in young and senescent pea plants. Plant Physiol. 136:2722-2733.

Curie, C. and J.F. Briat. 2003. Iron transport and signaling in plants. Annu. Rev. Plant Biol. 54:183-206.

Davies, P.J. 2004. Regulatory factors in hormone action: Level, location and signal transduction, p. 16-35. In: P.J. Davies (ed.). Plant hormones. Biosynthesis, signal transduction, action! Kluwer Academic Publishers, Dordrecht, The Netherlands.

De la Guardia, M.D., E. Alcántara, and M. Fernández. 1988. Iron reduction by sunflower roots under iron stress, p. 430. In: F.L. Crane, D.J. Morré, and H. Löw (eds.). Proceedings NATO advanced research workshop on plasma membrane oxidoreductases in control of animal and plant growth. Plenum Press, New York.

Dobrev, P.I. and M. Kaminek. 2002. Fast and efficient separation of cytokinins from auxin and abscisic acid and their purification using mixed-mode solid-phase extraction. J. Chromatography 950:21-29. Forbush, B. 1983. Assay of Na,K-ATPase in plasma membrane preparations: Increasing the permeability of membrane vesicles using sodium dodecyl sulfate buffered with bovine serum albumin. Anal. Biochem. 128:159-163.

García, M.J., F.J. Romera, R. Pérez-Vicente, C. Lucena, and E. Alcántara. 2007. Ferric reductase and iron transporter gene expression in different arabidopsis ethylene mutants, p. 401-403. In: A. Ramina, C. Chang, J. Giovannoni, H. Klee, P. Perata, and E. Woltering (eds.). Advances in plant ethylene research. Proceedings of the 7th international symposium on the plant hormone ethylene. Springer, Dordrecht, The Netherlands.

Graziano, M. and L. Lamattina. 2007. Nitric oxide accumulation is required for molecular and physiological responses to iron deficiency in tomato roots. Plant J. 52:949-960.

Graziano, M., M.V. Beligni, and L. Lamattina. 2002. Nitric oxide improves internal iron availability in plants. Plant Physiol. 130:1852-1859. Han, Z.H., C.Q. Han, X.F. Xu, and Q. Wang. 2005. Relationship between iron deficiency stress and endogenous hormones in ironefficient versus inefficient apple genotypes. J. Plant Nutr. 28:18871895.

Hansen, N.C., B.G. Hopkins, J.W. Ellsworth, and V.D. Jolley. 2006. Iron nutrition in field crops, p. 23-59. In: L.L. Barton and J. Abadía (eds.). Iron nutrition in plants and rhizospheric microorganisms. Springer, Dordrecht, The Netherlands.

Kawai, S. and S. Alam. 2006. Iron stress response and composition of xylem sap of strategy II plants, p. 289-309. In: L.L. Barton and J. Abadía (eds.). Iron nutrition in plants and rhizospheric microorganisms. Springer, Dordrecht, The Netherlands.

Landsberg, E.C. 1981a. Energy driven $\mathrm{H}^{+}$efflux pump in sunflower roots: Activated by Fe-deficiency stress. Plant Physiol. 67:702. (Abstr.).

Landsberg, E.C. 1981b. Fe stress induced transfer cell formation: Regulated by auxin? Plant Physiol. 67:563. (Abstr.).

Landsberg, E.C. 1981c. Organic acid synthesis and release of hydrogen ions in response to Fe deficiency stress of mono- and dicotyledonous plant species. J. Plant Nutr. 3:579-591.

Landsberg, E.C. 1984. Regulation of iron-stress-response by whole plant activity. J. Plant Nutr. 7:609-621.

Li, C.J., X.P. Zhu, and F.S. Zhang. 2000. Role of shoot in regulation of iron deficiency responses in cucumber and bean plants. J. Plant Nutr. 23:1809-1818.

Li, X. and Ch. Li. 2004. Is ethylene involved in regulation of root ferric reductase activity of dicotyledonous species under iron deficiency? Plant Soil 261:147-153.

Lobréaux, S., T. Hardy, and J.F. Briat. 1993. Abscisic acid is involved in the iron-induced synthesis of maize ferritin. EMBO J. 12:651-657.
Lucena, C., B.M. Waters, F.J. Romera, M.J. García, M. Morales, E. Alcántara, and R. Pérez-Vicente. 2006. Ethylene could influence ferric reductase, iron transporter, and $\mathrm{H}^{+}$-ATPase gene expression by affecting FER (or FER-like) gene activity. J. Expt. Bot. 57:41454154.

Lucena, J.J. 2006. Synthetic iron chelates to correct iron deficiency in plants, p. 103-128. In: L.L. Barton and J. Abadía (eds.). Iron nutrition in plants and rhizospheric microorganisms. Springer, Dordrecht, The Netherlands.

Murgia, I., M. Delledonne, and C. Soave. 2002. Nitric oxide mediates iron-induced ferritin accumulation in arabidopsis. Plant J. 30:521-528.

Nolan, T., R.E. Hands, W. Ogunkolade, and S.A. Bustin. 2006. SPUD: A quantitative PCR assay for the detection of inhibitors in nucleic acid preparations. Anal. Biochem. 351:308-310.

Pfaffl, M.W., G.W. Horgan, and L. Dempfle. 2002. Relative expression software tool (RESTC) for group-wise comparison and statistical analysis of relative expression results in real-time PCR. Nucleic Acids Res. 30:9 e36.

Pinton, R., S. Cesco, S. Santi, F. Agnolon, and Z. Varanini. 1999. Water-extractable humic substances enhance iron deficiency responses by Fe-deficient cucumber plants. Plant Soil 210:145-157.

Robin, A., G. Vansuyt, R. Hinsinger, J.M. Meyer, J.F. Briat, and P. Lemanceau. 2008. Iron dynamics in the rhizosphere: Consequences for plant health and nutrition, p. 183-225. In: D.L. Sparks (ed.). Advances in agronomy, Vol. 99. Elsevier Academic Press, San Diego. Rombolà, A.D. and M. Tagliavini. 2006. Iron nutrition of fruit tree crops, p. 61-83. In: L.L. Barton and J. Abadía (eds.). Iron nutrition in plants and rhizospheric microorganisms. Springer, Dordrecht, The Netherlands.

Romera, F.J. and E. Alcántara. 2004. Ethylene involvement in the regulation of $\mathrm{Fe}$-deficiency stress responses by strategy I plants. Funct. Plant Biol. 31:315-328.

Romera, F.J., C. Lucena, and E. Alcántara. 2006. Plant hormones influencing iron uptake in plants, p. 251-278. In: L.L. Barton and J. Abadía (eds.). Iron nutrition in plants and rhizospheric microorganisms. Springer, Dordrecht, The Netherlands.

Romera, F.J., E. Alcántara, and M.D. De la Guardia. 1999. Ethylene production by Fe-deficient roots and its involvement in the regulation of Fe-deficiency stress responses by strategy I plants. Ann. Bot. (Lond.) 83:51-55.

Römheld, V. and H. Marschner. 1986. Mobilization of iron in the rhizosphere of different plant species. Adv. Plant Nutr. 2:155-204.

Rubio, V., R. Bustos, M.L. Irigoyen, X. Cardona-López, M. RojasTriana, and J. Paz-Ares. 2009. Plant hormones and nutrient signaling. Plant Mol. Biol. 69:361-373.

Santi, S., G. Locci, R. Monte, R. Pinton, and Z. Varanini. 2003. Induction of nitrate uptake in maize roots: Expression of a putative high-affinity nitrate transporter and plasma membrane $\mathrm{H}^{+}$-ATPase isoforms. J. Expt. Bot. 54:1851-1864.

Santi, S., S. Cesco, Z. Varanini, and R. Pinton. 2005. Two plasma membrane $\mathrm{H}^{+}$-ATPase genes are differentially expressed in irondeficient cucumber plants. Plant Physiol. Biochem. 43:287-292.

Schmidt, W. 1994. Effects of various inhibitors on in vivo reduction by Plantago lanceolata L. roots. Plant Soil 165:207-212.

Schmidt, W. 2006. Iron stress responses in roots of strategy I plants, p. 229-250. In: L.L. Barton and J. Abadía (eds.). Iron nutrition in plants and rhizospheric microorganisms. Springer, Dordrecht, The Netherlands.

Schmidt, W. and M. Bartels. 1996. Formation of root epidermal transfer cells in plantago. Plant Physiol. 110:217-225.

Schmidt, W., A. Schikora, A. Pich, and M. Bartels. 2000a. Hormones induce an Fe-deficiency-like root epidermal cell pattern in the Feinefficient tomato mutant fer. Protoplasma 213:67-73.

Schmidt, W., J. Tittel, and A. Schikora. 2000b. Role of hormones in the induction of iron deficiency responses in arabidopsis roots. Plant Physiol. 122:1109-1118.

Schmidt, W., W. Michalke, and A. Schikora. 2003. Proton pumping by tomato roots: Effect of Fe deficiency and hormones on the activity 
and distribution of plasma membrane $\mathrm{H}^{+}$-ATPase in rhizodermal cells. Plant Cell Environ. 26:361-370.

Séguéla, M., J.F. Briat, G. Vert, and C. Curie. 2008. Cytokinins negatively regulate the root iron uptake machinery in arabidopsis through a growth-dependent pathway. Plant J. 55:289-300.

Séstak, Z., J. Càtsky, and P. Jarvis. 1971. Plant photosynthetic production: Manual of methods. Dr. W. Junk Publishers, The Hague, The Netherlands.

Varanini, Z., R. Pinton, M.G. De Biasi, S. Astolfi, and A. Maggioni. 1993. Low molecular weight humic substances stimulate $\mathrm{H}^{+}$-ATPase activity of plasma membrane vesicles isolated from oat (Avena sativa L.) roots. Plant Soil 153:61-69.

Vert, G., J.F. Briat, and C. Curie. 2003. Dual regulation of the arabidopsis high-affinity root uptake system by local and longdistance signals. Plant Physiol. 132:796-804.

Waters, B.M., C. Lucena, F.J. Romera, G.G. Jester, A.N. Wynn, C.L. Rojas, E. Alcántara, and R. Pérez-Vicente. 2007. Ethylene involvement in the regulation of the $\mathrm{H}^{+}$-ATPase CsHAl gene and of the new isolated ferric reductase CsFRO1 and iron transporter CsIRT1 genes in cucumber plants. Plant Physiol. Biochem. 45:293-301. 